\title{
Estatísticas sobre rendimento e características sociodemográficas no Brasil
}

Palavras-chave: estatísticas

demográficas; estatísticas

escolares; rendimento escolar.

As tabelas apresentadas a seguir foram elaboradas com base nas estatísticas sobre ocupação, rendimento e escolaridade, produzidas pelo IBGE a partir da Pesquisa Nacional por Amostra de Domicílios de 2001. Elas permitem investigar as relações entre condição de ocupação, rendimento e escolaridade da população, fornecendo subsídio valioso para um diagnóstico sobre o tema, e retratam a forte desigualdade social existente no País.

Também apresentam combinações de fatores essenciais para entendimento do fenômeno, destacando-se entre eles cor ou raça, regiões geográficas, regiões metropolitanas, unidades da Federação, gênero e idade. Sua análise permite constatar que a mudança do patamar de escolaridade do brasileiro, tão importante para a melhoria da condição social da população e, conseqüentemente, para o desenvolvimento do País, transcende os bancos escolares e se insere numa questão social mais ampla.

Os dados mostram que há forte relação entre rendimento e escolaridade, registram que o desemprego alcança todas as faixas de escolaridade e demonstram a contundência da desigualdade social brasileira a partir das informações sobre rendimento entre os extratos mais pobres e mais ricos da população ocupada. Há um abismo entre eles, revelado, inclusive, quando se analisa a escolaridade dos jovens entre 18 e 24 anos - ou seja, quanto maior o rendimento maior a escolaridade.

Muito se diz sobre ser o Brasil um país plural, onde diferenças raciais e culturais convivem em harmonia. Entretanto, há um viés nessa leitura que deve ser adequadamente tratado, para que as desigualdades sociais não se configurem uma dimensão negativa dessa pluralidade.

Nesse sentido, deve-se ressaltar a importância da ação do governo, da família e da escola para garantir um ensino de qualidade a todos os brasileiros, contribuindo, efetivamente, para a igualdade de oportunidades da população, e permitindo-lhe beneficiar-se dos aspectos positivos de sua diversidade. 
Tabela 1 - População ocupada, total e sua respectiva distribuição percentual, por classes de rendimento médio mensal de todos os trabalhos em salário mínimo, segundo as Grandes Regiões, Unidades da Federação e Regiões Metropolitanas - 2001

\begin{tabular}{|c|c|c|c|c|c|c|c|}
\hline \multirow{3}{*}{$\begin{array}{l}\text { Grandes Regibes, } \\
\text { Unidades de Federaçà e } \\
\text { Regloes Metropolitanas }\end{array}$} & \multicolumn{7}{|c|}{ Populaçãe ocupada } \\
\hline & \multirow{2}{*}{$\begin{array}{l}\text { Total } \\
\text { (1) }\end{array}$} & \multicolumn{6}{|c|}{$\begin{array}{l}\text { Classes de rendimento mbdio mensal de todos os } \\
\text { trabalhos em salario minimo }(\mathrm{W})\end{array}$} \\
\hline & & Ats $1 / 2$ & $\begin{array}{c}\text { Mais do } \\
1 / 2 \text { a } 1\end{array}$ & $\begin{array}{c}\text { Mais de } \\
1 \text { a } 2\end{array}$ & $\begin{array}{c}\text { Mais de } \\
2 \text { a } 3\end{array}$ & $\begin{array}{c}\text { Mais de } \\
3 \text { a } 5\end{array}$ & $\begin{array}{l}\text { Mais de } \\
5\end{array}$ \\
\hline Brasil (2) & 75450692 & 7,8 & 16,3 & 26,0 & 12,9 & 11,0 & 12,9 \\
\hline Norte (3) & 3720594 & 6,4 & 20,6 & 31,2 & 13,2 & 10,5 & 10,5 \\
\hline Rondônia & 379120 & 3.8 & 19.0 & 33,3 & 14,2 & 11,3 & 12,6 \\
\hline Acre & 158344 & 8.5 & 18.0 & 24,8 & 11,7 & $\mathbf{B}, \mathbf{B}$ & 16,5 \\
\hline Amazonas & 793223 & 3,9 & 17,3 & 34,3 & 14,2 & 12,4 & 11,7 \\
\hline Roraima & 107940 & 1.4 & 19.6 & 31,5 & 16,7 & 13,5 & 12,6 \\
\hline Pard & 1721463 & 7.6 & 23.2 & 31,8 & 12,0 & $\mathrm{~B}, 7$ & 8,5 \\
\hline Regiso Motropolitana de Belem & 685788 & 5.7 & 21,3 & 33,3 & 13,6 & 9,9 & 12,0 \\
\hline Amspd & 140906 & 0.2 & 7,6 & 19,7 & 25,8 & 25,9 & 16,1 \\
\hline Tocantins & 570194 & 120 & 23.2 & 23,4 & 8,8 & 6,1 & 7,0 \\
\hline Nordeste & 20547577 & 16,2 & 24,8 & 21,3 & 6,6 & 5,0 & 5,4 \\
\hline Maranhalo & 2562367 & 16.6 & 24,1 & 18,4 & 5,9 & 4,2 & 4,8 \\
\hline Piaul & 1287021 & 23,5 & 20.2 & 16,9 & 6,7 & 4,1 & 3,7 \\
\hline Ceara & 3324940 & 21,0 & 24,1 & 19,5 & 5,9 & 4,6 & 5,1 \\
\hline Regiso Motropoltana de Fortaleza & 1247016 & 10,6 & 24,2 & 30,2 & 10,0 & 8,0 & 10,2 \\
\hline Rio Grande do Narte & 1142202 & 11,2 & 259 & 26,2 & 8,1 & 6,0 & 6,9 \\
\hline Paraiba & 1352024 & 15,1 & 27,8 & 19,7 & 5,9 & 4,4 & 5,7 \\
\hline Pernambudo & 3327392 & 13,1 & 20,1 & 26,4 & 7,2 & 5,6 & 6,7 \\
\hline Regiso Metropeltana de Recife & 1297438 & 8,5 & 17,5 & 36,8 & 10,4 & 9,0 & 12,5 \\
\hline Alagoas & 1145039 & 14,4 & 27,3 & 21,3 & 6,0 & 4,5 & 4,5 \\
\hline Sergipe & 739536 & 12,9 & 24,1 & 26,5 & 8,3 & 7,2 & 6,1 \\
\hline Bahia & 5667066 & 15,4 & 279 & 20,3 & 6,8 & 5,3 & 5,4 \\
\hline Regiso Motropoltana de Salvadar & 1335253 & 9,5 & 22,4 & 28,1 & 12,0 & 10,0 & 12,3 \\
\hline Sudeste & 32650283 & 4,3 & 12,3 & 27,0 & 16,1 & 14,3 & 17,7 \\
\hline Mnas Gerais & 8 334913 & 8.6 & 19.9 & 27,5 & 11,4 & 9,0 & 10,2 \\
\hline Regise Metrapolkana de lisla Heriasnta & 1 ga1 016 & 42 & 14,7 & 31,9 & 14,1 & 12,0 & 15,0 \\
\hline Espinto Santo & 1481084 & 6,1 & 18.2 & 29,3 & 10,3 & 8,9 & 10,6 \\
\hline Rio de Janeiro & 6049007 & 2,9 & 11,7 & 29,9 & 16,4 & 15,5 & 18,3 \\
\hline Regiso Motropoltana do Rio de Janeiro & 4508829 & 23 & 9.9 & 28,8 & 16,7 & 16,6 & 20,0 \\
\hline Sao Paulo & 16785279 & 2.4 & 8,1 & 25,5 & 18,9 & 16,9 & 21,8 \\
\hline Regiso Metropolitana de Sso Paulo & 7961044 & 1.6 & 6.0 & 22,3 & 19,9 & 18,3 & 25,3 \\
\hline Sul & 12872954 & 4,5 & 11,5 & 27,7 & 14,6 & 12,8 & 13,1 \\
\hline Parand & 4723546 & 5.2 & 13.6 & 27,5 & 13,7 & 11,4 & 13,2 \\
\hline Regiso Motrapoitana de Curitba & 1326604 & 2.4 & 8,4 & 28,6 & 18,0 & 15,9 & 19,0 \\
\hline Santa Catarina & 2814131 & 28 & 7,9 & 28,8 & 17,8 & 14,7 & 13,9 \\
\hline Rio Grande do Sul & 5335278 & 4,8 & 11,6 & 27,4 & 13,7 & 12,9 & 12,7 \\
\hline Regiso Metropolitana de Porta Alegre & 1813480 & 2,9 & 9.1 & 29,2 & 18,1 & 16,3 & 18,8 \\
\hline Centro-Oeste & 5508698 & 5,5 & 16,7 & 30,8 & 13,5 & 10,4 & 14,4 \\
\hline Mato Grossa do Sul & 961168 & 6.6 & 15.5 & 33,8 & 13,2 & 10,1 & 11.8 \\
\hline Mato Grosso & 1238843 & 3.6 & 15.2 & 29,8 & 15,0 & 10,9 & 12,2 \\
\hline Goias & 2401611 & 7.6 & 20,3 & 30,9 & 13,2 & 9,3 & 10,4 \\
\hline Distrito Federal & 907076 & 1.2 & 10.5 & 28,5 & 12,4 & 13,3 & 30,6 \\
\hline
\end{tabular}

Fonte: Pesqusa nacional por amostra de domicilios 2001: microdados. Rio de Janeiro: IBGE, 2002. 1 CD.ROM. Nota: Comproendem as pessoas de 10 anos e mas de idade moradoras em domicilos particulares.
(1) Inclusive som declaraça de renda.
(2) Exclushe a populaçăo rural de Rondónia, Acre, Amazonas, Roraima, Para e Amapd.
(3) Exclusive a populaçào nural. 
Tabela 2 - Distribuição dos $40 \%$ mais pobres e dos $10 \%$ mais ricos da população ocupada, seus respectivos rendimentos médios mensais em reais e em salário mínimo e relação entre rendimentos médios, segundo as Grandes Regiões, Unidades da Federação e Regiões Metropolitanas - 2001

\begin{tabular}{|c|c|c|c|c|c|c|c|}
\hline \multirow[b]{2}{*}{$\begin{array}{l}\text { Grandes Regibes, } \\
\text { Unidades de Federaça e } \\
\text { Regioes Motropolitanas }\end{array}$} & \multicolumn{3}{|c|}{$\begin{array}{l}40 \% \text { mais pobres da } \\
\text { populaçáo ocupada }\end{array}$} & \multicolumn{3}{|c|}{$\begin{array}{l}10 \% \text { mais ricos da } \\
\text { populagaso ocupada }\end{array}$} & \multirow[b]{2}{*}{$\begin{array}{l}\text { Relaça } \\
\text { entre } \\
\text { rendi. } \\
\text { mentos } \\
\text { modilos } \\
\text { (B/A) }\end{array}$} \\
\hline & $\begin{array}{l}\text { Total } \\
\text { (A) }\end{array}$ & $\begin{array}{l}\text { Rendi- } \\
\text { mento } \\
\text { médio } \\
\text { mensal } \\
\text { em reais }\end{array}$ & $\begin{array}{l}\text { Rend: } \\
\text { mento } \\
\text { medio } \\
\text { mensal } \\
\text { em } \\
\text { salário } \\
\text { minimo }\end{array}$ & $\begin{array}{l}\text { Total } \\
\text { (B) }\end{array}$ & $\begin{array}{l}\text { Rendi: } \\
\text { mento } \\
\text { midio } \\
\text { mensal } \\
\text { em reals }\end{array}$ & $\begin{array}{l}\text { Rendi- } \\
\text { mento } \\
\text { médio } \\
\text { mensal } \\
\text { em } \\
\text { salárilo } \\
\text { minimo }\end{array}$ & \\
\hline Brasil (1) & 26391770 & 149,85 & 0,83 & 6597963 & 2744,30 & 15,25 & 18,31 \\
\hline Norte (2) & 1375331 & 150,43 & 0,84 & $343 \mathrm{BB7}$ & 2279,62 & 12,65 & 15,15 \\
\hline Renobria & 142729 & 171,04 & 0,95 & 35725 & $2393,5 T$ & 13,30 & 13,99 \\
\hline Acre & 55830 & 144,62 & 0,80 & 13979 & 3653,42 & 19,80 & 24,64 \\
\hline Amazonas & 297793 & 170,39 & 0,95 & 74502 & 2397,95 & 13,32 & 14,07 \\
\hline Roraima & 41243 & 185,17 & 1,03 & 10309 & 1928,47 & 10,71 & 10,41 \\
\hline Pard & 631601 & 140,88 & 0,78 & 157934 & 2013,21 & $11,1 \mathrm{~B}$ & 14,29 \\
\hline Regiao Metropolitana de Beiem & 262719 & 155,89 & 0,87 & 65683 & 2509,65 & 13,94 & 16,10 \\
\hline Amapa & 53710 & 291,51 & 1,62 & 13429 & 2257,76 & 12,60 & 7,78 \\
\hline Tocartins & 335562 & 118,71 & 0,66 & 83902 & 2364,15 & 13,13 & 19,91 \\
\hline Nordeste & 6525844 & 90,80 & 0,50 & 1631462 & 1721,77 & 9,57 & 18,96 \\
\hline Maranhào & 758431 & $89,2 \mathrm{~B}$ & 0,50 & 189605 & 1593,26 & 8.85 & 17,85 \\
\hline Pisul & 386158 & 59,17 & 0,33 & 95643 & 1345,92 & 7,48 & 22,75 \\
\hline Ceara & 1067686 & 71,03 & 0,39 & 255971 & 1699,45 & 9,44 & 23,93 \\
\hline Regia Metropolitana de Fortaleza & 465603 & 128,16 & 0,71 & 116433 & 2546,22 & 14,15 & 19,87 \\
\hline Rus Grande do Norte & 384884 & 119,46 & 0,66 & 95295 & 1912,92 & 10,63 & 16,01 \\
\hline Parabo & 425201 & 95,91 & 0,53 & 105384 & 1845,55 & 10,25 & 19,24 \\
\hline Pemambuco & 1053245 & 105,96 & 0,59 & 253320 & 1955,43 & 10,85 & 18,46 \\
\hline Regiaso Metropolitana de Recife & 491468 & 141,30 & 0,79 & 122911 & 2720,51 & 15,11 & 19,25 \\
\hline Alagoas & 357115 & 92,89 & 0,52 & 89385 & 1494,94 & 8,31 & 16,09 \\
\hline Sergipe & 252081 & 110,60 & 0,61 & 63050 & 1652,25 & 9,18 & 14,94 \\
\hline Bahia & 1838775 & 94,64 & 0,53 & 459807 & 1703,90 & 9.47 & 18,00 \\
\hline Regiao Metropoltana de Salvador & 503620 & 138,08 & 0,77 & 125927 & 2915,72 & 16,20 & 21,12 \\
\hline Sudeste & 11958115 & 196,93 & 1,09 & 2959546 & 3177,88 & 17,65 & 16,14 \\
\hline Minas Gera's & 2887560 & 140,05 & 0,78 & 722095 & 2207,81 & 12,27 & 15,76 \\
\hline Regiäo Metropolitana de Bela Herizonte & 741888 & 183,78 & 1,02 & 185528 & 2808,45 & 15,60 & 15,28 \\
\hline Espirito Santo & 494064 & 151,72 & 0,84 & 123576 & 2477,04 & 13,76 & 16,33 \\
\hline Rio de Janeira & 2287428 & 208,34 & 1,16 & 571953 & 3128,03 & 17,38 & 15,01 \\
\hline Regiao Metropolitana do Fuo de Janeiro & 1700823 & 223,63 & 1,24 & 425295 & 3392,41 & 18.85 & 15,17 \\
\hline São Paulo & 6287123 & 242,60 & 1,35 & 1571921 & 3619,67 & 20,11 & 14,92 \\
\hline Regläo Metropoltana de Sao Paulo & 2970266 & 275,99 & 1,53 & 742720 & 4129,55 & 22,94 & 14,96 \\
\hline Sult & 4337783 & 186,80 & 1,04 & 1084574 & 2695,65 & 14,95 & 14,44 \\
\hline Parand & 1597140 & 171,97 & 0,96 & 399434 & 2822,51 & 15,68 & 16,41 \\
\hline Regia Metropoltana de Curisba & 489912 & 227,27 & 1,26 & 122497 & 3353,91 & 18,69 & $14, \mathrm{BO}$ \\
\hline Santa Catarina & 967065 & 221,34 & 1,23 & 241805 & 2456,76 & 13,65 & 11,10 \\
\hline Rio Grande do Sul & 1773238 & 182,67 & 1,01 & 443334 & 2714,11 & 15,05 & 14,85 \\
\hline Regiao Metropolitana de Porto Alegre & 684513 & 224,10 & 1,24 & 171173 & 3318,12 & 18,43 & 14,81 \\
\hline Centro-Oeste & 2010073 & 168,59 & 0,94 & 502583 & 3093,59 & 17,19 & 18,35 \\
\hline Mato Grosso do Sul & 349966 & 161,36 & 0,90 & 87494 & 2738,74 & 15,22 & 16,97 \\
\hline Mato Grosso & 428682 & 182,18 & 1,01 & 107234 & 2789,74 & 15,50 & 15,31 \\
\hline Goiss & 880419 & 149,31 & 0,83 & 220114 & 2440,83 & 13,55 & 16,35 \\
\hline Distrito Federal & 350827 & 233,16 & 1,30 & 87732 & 4639,89 & 25,78 & 19,90 \\
\hline
\end{tabular}

Fonte: Pesquisa nacianal por amostra de domicilos 2001: microdados. Rio de Janeiro: IeGE, 2002. 1 CD.ROM. Nota: Rendimerno mensal de todos os trabalhos das pessoas ocupadas de 10 anos e mais de idade com rendimento.

(1) Exclusive a populaçso rural de Rondónia, Acre, Amazonas, Rorama, Para e Amapd.

(2) Exclusive a populap̧so rural. 
Tabela 3 - Distribuição do rendimento dos $50 \%$ mais pobres e do $1 \%$ mais rico em relação ao total de rendimentos, segundo as Grandes Regiões, Unidades da Federação e Regióes Metropolitanas - 2001

\begin{tabular}{|c|c|c|}
\hline \multirow{2}{*}{$\begin{array}{l}\text { Grandes Regiōes, } \\
\text { Unidades da Federação } \\
\text { e Regiōes Metropolitanas }\end{array}$} & \multicolumn{2}{|c|}{ Rendimento $(\%)$} \\
\hline & $50 \%$ mais pobres & $1 \%$ mais rico \\
\hline Brasil (1) & 14,8 & 13,3 \\
\hline Norte (2) & 16,7 & 13,7 \\
\hline RondÊnia & 17,4 & 13,2 \\
\hline Acre & 12,2 & 14,2 \\
\hline Amazonas & 17,6 & 12,8 \\
\hline Roraima & 19,9 & 10,2 \\
\hline Pará & 17,4 & 13,7 \\
\hline Regiảo Metropolitana de Belem & 16,2 & 13,6 \\
\hline Amapá & 23.5 & 7,8 \\
\hline Tocantins & 14,4 & 17,9 \\
\hline Nordeste & 15,3 & 15,4 \\
\hline Maranh̆ão & 15,8 & 15,6 \\
\hline Piaui & 13,4 & 13,0 \\
\hline Ceará & 13,6 & 17,1 \\
\hline Regiảo Metropolitana de Fortaleza & 14,3 & 16,4 \\
\hline Rio Grande do Norte & 16,6 & 14,2 \\
\hline Paraiba & 15,5 & 15,5 \\
\hline Pernambuco & 15,2 & 14,9 \\
\hline Regiảo Metropolitana de Recife & 14,5 & 13,8 \\
\hline Alagoas & 17,1 & 13,9 \\
\hline Sergipe & 16,8 & 11,3 \\
\hline Bahia & 15,8 & 15,8 \\
\hline Regiảo Metropolitana de Salvador & 13,8 & 15,0 \\
\hline Sudeste & 15,9 & 12,5 \\
\hline Minas Gerais & 16.2 & 12,8 \\
\hline Regiảo Metropolitana de Belo Horizonte & 16,3 & 11,3 \\
\hline Espirito Santo & 16,0 & 12,5 \\
\hline Rio de Janeiro & 16,6 & 11,8 \\
\hline Regiảo Metropolitana do Rio de Janeiro & 16,4 & 11,9 \\
\hline São Paulo & 16,6 & 12,2 \\
\hline Regiảo Metropolitana de Sảo Paulo & 16,5 & 12,4 \\
\hline Sul & 17,1 & 12,4 \\
\hline Paraná & 15,9 & 13,7 \\
\hline Regišso Metropolitana de Curitiba & 16,8 & 12,6 \\
\hline Santa Catarina & 19,7 & 10,2 \\
\hline Rio Grande do Sul & 16,8 & 12,5 \\
\hline Regiảo Metropolitana de Porto Alegre & 16,8 & 11,4 \\
\hline Centro-Oeste & 15,0 & 13,8 \\
\hline Mato Grosso do Sul & 16,0 & 15,0 \\
\hline Mato Grosso & 17,0 & 14,3 \\
\hline Goiás & 16.3 & 15,2 \\
\hline Distrito Federal & 12,8 & 9,2 \\
\hline
\end{tabular}

Fonte: Pesquisa nacional par amostra de domiclios 2001: microdados. Rio de Janeiro: IBGE, 2002. 1 CD-ROM. Nota: Rendimento de todas as fontes das pessoas de 10 anos e mais de idade com rendimento.

(1) Exclusive a populaçấo rural de Rondónia, Acre, Amazonas, Roraima, Pará e Amapá.

(2) Exclusive a populaçẩo rural. 


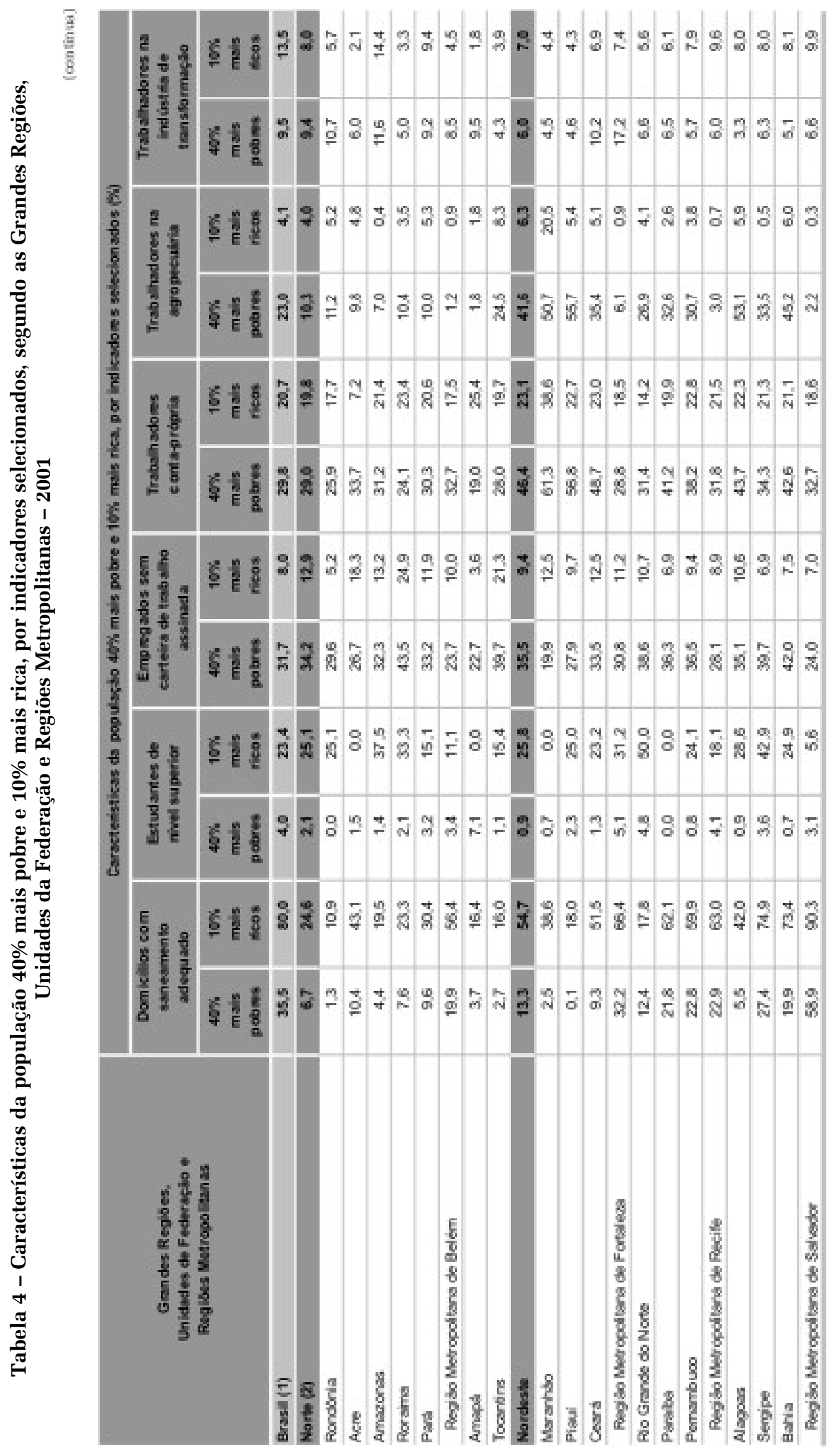




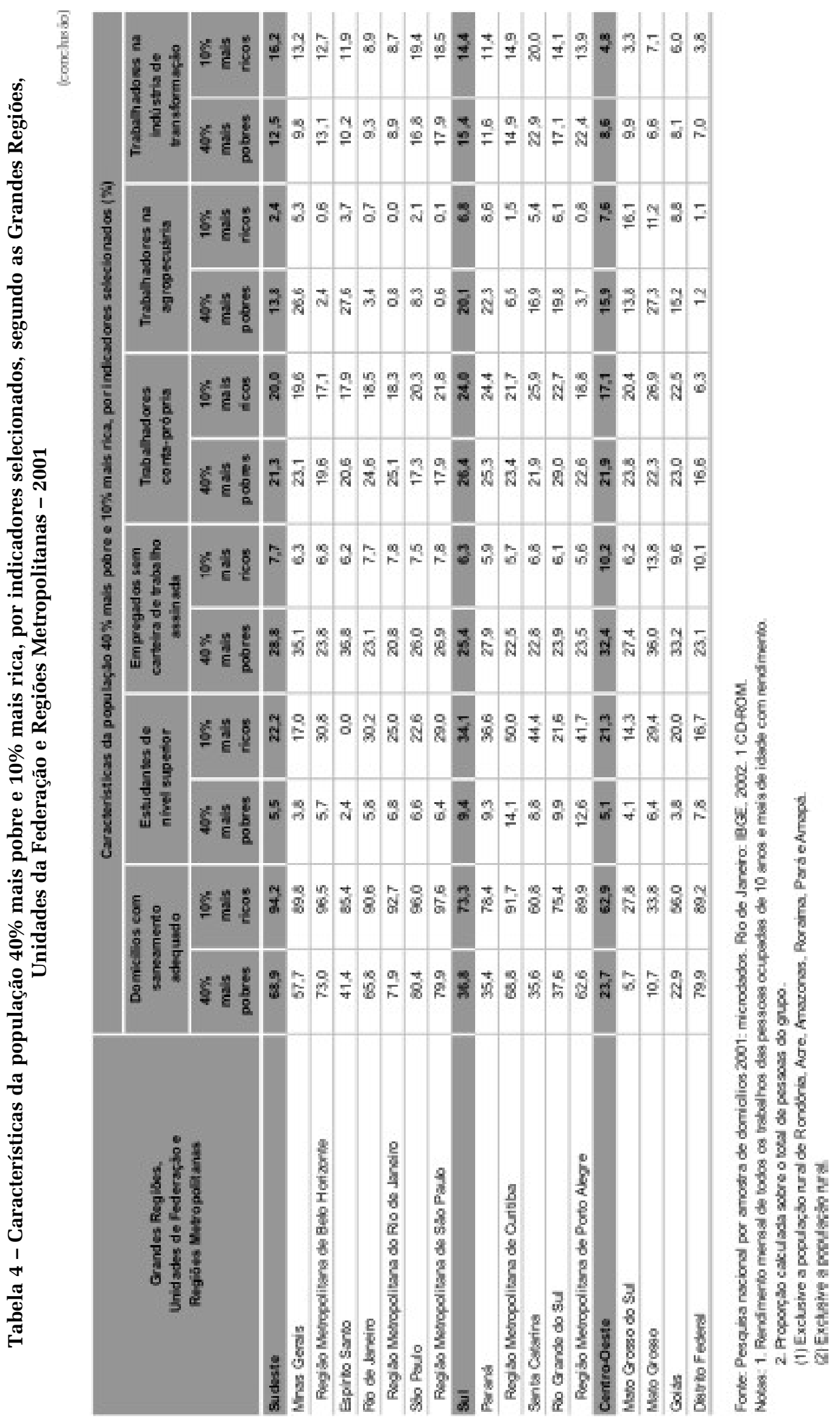




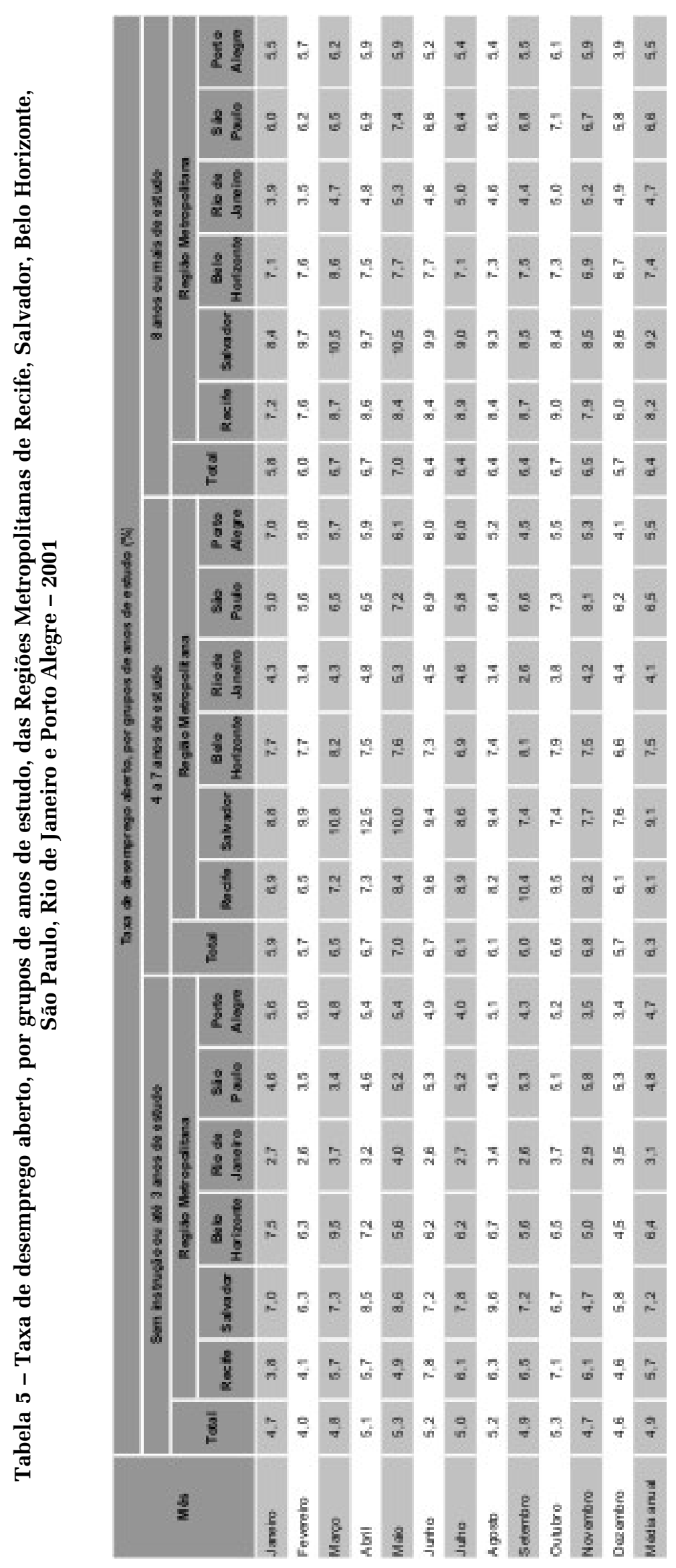


Tabela 6 - Taxa de escolarização das pessoas de 7 a 14 anos de idade, por quintos de rendimento mensal familiar per capita, segundo as Grandes Regiões,

Unidades da Federação e Regiões Metropolitanas - 2001

\begin{tabular}{|c|c|c|c|c|c|}
\hline \multirow{2}{*}{$\begin{array}{l}\text { Grandes Regices, } \\
\text { Unidades da Foderaça e } \\
\text { Regloes Metropolitanas }\end{array}$} & \multicolumn{5}{|c|}{$\begin{array}{l}\text { Taxa de escolarizagào das pessoas de } 7 \text { a } 14 \text { anes de idade, por } \\
\text { quintos de rendimento mensal familliar per capita (\%) }\end{array}$} \\
\hline & 1" quinto & $2^{*}$ quinto & $3^{\circ}$ quinto & 4 quinto & 5. quilito \\
\hline Brasil (1) & 93,7 & 95,0 & 96,5 & 97,7 & 99,4 \\
\hline Norte (2) & 92,7 & 93,2 & 94,8 & 97,2 & $9 \mathrm{~B}, 6$ \\
\hline Rondonia & 91,9 & 93,8 & 91,3 & 95,1 & 99,4 \\
\hline Acre & 93,1 & 92,1 & 56,1 & 95,1 & 99,0 \\
\hline Amazonas & 93,4 & 91,3 & 94,5 & 99,3 & 98,2 \\
\hline Roraima & 96,2 & 96,3 & 56.2 & 98,1 & 98,2 \\
\hline Para & 92,6 & 92,7 & 96,4 & 97,6 & 97,3 \\
\hline Regiso Motrapoltana de Belém & 91,6 & 94,2 & 56.5 & 98,0 & 99,7 \\
\hline Amspd & 100,0 & 97,2 & 100,0 & 100,0 & 100,0 \\
\hline Tocantins & 90,3 & 96,9 & 91.4 & 97,5 & 99,5 \\
\hline Nordeste & 93,1 & 94,4 & 94,7 & 95,8 & 98,0 \\
\hline Moranhào & 93,6 & 94,9 & 93.2 & 95,3 & 97,6 \\
\hline Piaul & 95,2 & 96,3 & 96,7 & 95,7 & 98,9 \\
\hline Ceard & 94,1 & 96,4 & 56,3 & 95,6 & 98,6 \\
\hline Regiso Motropolitana de Fortaleza & 93,9 & 95,6 & 56.2 & 98,1 & 95,9 \\
\hline Rio Grande do Narte & 90,6 & 94,7 & 97,4 & 95,3 & 99,5 \\
\hline Paraiba & 94,4 & 96,2 & 56,3 & 97,0 & 98,5 \\
\hline Pernambudo & 91,8 & 92,8 & 939 & 93,8 & 98,1 \\
\hline Regiso Metropolitana de Recife & 90,9 & $\mathbf{9 6 , 5}$ & 96,9 & 96,7 & 99,0 \\
\hline Alagoas & 90,5 & 91,0 & 50,1 & 93,8 & 98,6 \\
\hline Sergipe & 93,6 & 90,7 & 93.6 & 98,9 & 98,4 \\
\hline Bahia & 93,6 & 94,3 & 96.2 & 95,6 & 97,1 \\
\hline Regiso Metropolitana de Salvador & 93,1 & 94,3 & 97,3 & 97,8 & 98,8 \\
\hline Sudeste & 94,5 & 96,5 & 97,6 & 98,9 & 99,5 \\
\hline Mnas Gerais & 95,2 & 96,2 & 96.8 & 98,1 & 99,4 \\
\hline Regiso Metropoltana de Belo Horizente & 96,2 & 96,5 & se. 0 & 98,5 & 99,4 \\
\hline Espinto Santo & 93,5 & 94,9 & 94.0 & 972 & 98,6 \\
\hline Rio de Janeiro & 90,8 & 96,9 & 97.2 & 98,8 & 99,4 \\
\hline Regiso Metropeltana do Rio de Janeiro & 89,9 & 56,9 & 97,4 & 98,9 & 99,3 \\
\hline Saso Paulo & 95,5 & 97,7 & se. 2 & 99,0 & 99,7 \\
\hline Regiso Metropoltana de SSo Pado & 96,7 & ge, 4 & se, 7 & 99,5 & 99,3 \\
\hline Sul & 94,1 & 95,8 & 97,1 & 98,5 & 99,6 \\
\hline Parana & 92,7 & 96,2 & 56,7 & 98,1 & 99,8 \\
\hline Regiso Motropolitana de Curitba & 92,3 & 96,7 & 56.6 & 98,1 & 99,5 \\
\hline Santa Catarina & 96,3 & 97,1 & seg & 98,5 & 99,6 \\
\hline Rio Grande do Sul & 94,4 & 96,6 & 97.2 & 98,4 & 99,3 \\
\hline Regiso Motrapolitana de Porla Alegre & 91,1 & 94,7 & 56,3 & 98,6 & 99,4 \\
\hline Centro-Oeste & 94,9 & 96,8 & 97,2 & 97,3 & 99,2 \\
\hline Maso Grosso do Sul & 95,4 & 96,3 & 98.6 & 972 & 99,1 \\
\hline Mato Grosso & 95,5 & 96,3 & 96.5 & 96,7 & 99,2 \\
\hline Goias & 95,0 & 97,2 & 970 & 95,8 & 99,4 \\
\hline Distrito Federal & 94,2 & s8,1 & 56.2 & 100,0 & 99,0 \\
\hline
\end{tabular}

Fonte: Pesqusa nacional por amostra de damicilios 2001: microdados. Rio de Janeiro: 1BGE, 2002. 1 CO-ROM.

Nota: (1) Exclusive a populaçấo nural de Rondônia, Acre, Amazonas, Roraima, Para e Amapd.

(2) Exclusive a populsçáo rural. 
Tabela 7 - Taxa de escolarização das pessoas de 15 a 17 anos de idade, por quintos de rendimento mensal familiar per capita, segundo as Grandes Regiões, Unidades da Federação e Regiões Metropolitanas - 2001

\begin{tabular}{|c|c|c|c|c|c|}
\hline \multirow{2}{*}{$\begin{array}{l}\text { Grandes Regiōes, } \\
\text { Unidades da Federaçảo e } \\
\text { Regióes Metropolitanas }\end{array}$} & \multicolumn{5}{|c|}{$\begin{array}{l}\text { Taxa de escolarizaçáo das pessoas de } 15 \text { a } 17 \text { anos de idade, } \\
\text { por quintos de rendimento mensal familiar per capita }(\%)\end{array}$} \\
\hline & $1^{2}$ quinto & $2^{\circ}$ quinto & $3^{2}$ quinto & $4^{2}$ quinto & $5^{\circ}$ quinto \\
\hline Brasil (1) & 70,8 & 75,6 & 80,2 & 84,6 & 94,6 \\
\hline Norte (2) & 68,5 & 75,3 & 80,4 & 86,3 & 92,1 \\
\hline Rondânia & 67,2 & 75,4 & 70,5 & 82,0 & 96,8 \\
\hline Acre & 55.8 & 65,7 & 65.7 & 82,9 & 91,7 \\
\hline Amazonas & 70,0 & 77,3 & 88,2 & 89,1 & 93,7 \\
\hline Roraima & 90,9 & 77,3 & 91,3 & 90,9 & 95,6 \\
\hline Pará & 65,3 & 77,7 & 76,8 & 83,2 & 87,9 \\
\hline Regiāo Metropolitana de Belém & 75,3 & 86,1 & 82,2 & 92,7 & 93,4 \\
\hline Âmapj & 76,9 & 69,2 & 84,6 & 100,0 & 100,0 \\
\hline Tocantins & 80,8 & 77,2 & 79.8 & 86,1 & 89,9 \\
\hline Nordeste & 70,2 & 76,2 & 77,4 & 80,7 & 91,9 \\
\hline Maranhão & 63,5 & 70,7 & 87,1 & 80,2 & 90,5 \\
\hline Piaui & 72,6 & 82,2 & 80,6 & 83,6 & 95,9 \\
\hline Ceará & 75,5 & 79,5 & 77,0 & 81,8 & 89,9 \\
\hline Regiāo Metropolitana de Fortaleza & 80,6 & 81,7 & 82,9 & 86,9 & 93,8 \\
\hline Rio Grande do Norte & 70,3 & 77,0 & 77,0 & 81,1 & 97,3 \\
\hline Paraiba & 67,0 & 77,7 & 77,7 & 78,6 & 91,3 \\
\hline Pernambuco & 67,8 & 66,5 & 71,5 & 76,3 & 89,4 \\
\hline Regiāo Metropolitana de Recife & 68,1 & 78,5 & 83,3 & 88,2 & 91,4 \\
\hline Alagoas & 73,7 & 78,5 & 72,8 & 73,8 & 88,7 \\
\hline Sergipa & 65,2 & 76,8 & 64,3 & 79,7 & 94,3 \\
\hline Bahia & 72,2 & 79,1 & 81,2 & 83,8 & 93,0 \\
\hline Regiāo Metropolitana de Salvador & 77,8 & 89,6 & 87,6 & 90,8 & 97,3 \\
\hline Sudeste & 71,4 & 78,4 & 82,0 & 90,2 & 96,0 \\
\hline Minas Gerais & 71,0 & 72,2 & 77,0 & 78,8 & 94,9 \\
\hline Regiāo Metropolitana de Belo Horizonte & 73,2 & 83,4 & 86,5 & 89,9 & 97,8 \\
\hline Espirito Santo & 65,0 & 53,8 & 70,0 & 76,2 & 97,5 \\
\hline Rio de Janeiro & 71,0 & 83,8 & 83,2 & 92,8 & 96,4 \\
\hline Regiāo Metropolitana do Rio de Janeiro & 72,0 & 86,3 & 88,6 & 93,1 & 97,1 \\
\hline Sāo Paulo & 75,2 & 83,1 & 86,4 & 90,8 & 96,1 \\
\hline Regiāo Metropolitana de São Paulo & 79,7 & 89,5 & 89,9 & 93,7 & 96,2 \\
\hline Sul & 62,4 & 76,8 & 76,3 & 84,6 & 94,8 \\
\hline Paraná & 56,0 & 71,2 & 75,7 & 81,3 & 91,9 \\
\hline Regiāo Metropolitana de Curitiba & 54,8 & 70,6 & 78,8 & 82,4 & 94,1 \\
\hline Santa Catarina & 67,9 & 77,7 & 84,7 & 90,2 & 96,5 \\
\hline Rio Grande do Sul & 65,5 & 81,8 & 77,3 & 82,1 & 94,1 \\
\hline Regiāo Metropolitana de Porto Negre & 73,5 & 70,1 & 88,3 & 77,7 & 94,4 \\
\hline Centro-Oeste & 72,3 & 75,1 & 76,6 & 83,8 & 93,9 \\
\hline Mato Grossa da Sul & 68,4 & 76,6 & 67,5 & 71,4 & 90,9 \\
\hline Mato Grossa & 76,1 & 66,3 & 71,7 & 82,4 & 89,2 \\
\hline Goiás & 70,4 & 78,4 & 77,8 & 85,3 & 95,8 \\
\hline Distrito Federal & 74,2 & 83,5 & 90,0 & 90,1 & 99,2 \\
\hline
\end{tabular}

Fonte: Pesquisa nacional por amostra de domicilios 2001: microdados. Rio de Janeiro: IBGE, 2002. 1 CD-ROM. Nota: (1) Exclusive a populaçāo rural de Rondônia, Acre, Amazonas, Roraima, Pará e Amapá.

(2) Exclusive a populaçấo rural. 
Tabela 8 - Taxa de freqüência à escola ou creche das crianças de 0 a 6 anos de idade, por quintos de rendimento mensal familiar per capita, segundo as Grandes Regióes - 2001

\begin{tabular}{|c|c|c|c|c|c|c|}
\hline \multirow{2}{*}{ Grandes Regiōes } & \multicolumn{6}{|c|}{$\begin{array}{l}\text { Taxa de frequếncia à escola ou creche das crianças de } 0 \text { a } 6 \text { anos } \\
\text { de idade, por quintos de rendimento mensal familiar per capita (\%) }\end{array}$} \\
\hline & Total & $1^{\circ}$ quinto & $2^{a}$ quinto & $3^{\circ}$ quinto & $4^{\circ}$ quinto & $5^{\circ}$ quinto \\
\hline Brasil (1) & 34,9 & 26,5 & 29,7 & 32,3 & 36,6 & 48,8 \\
\hline Norte (2) & 30,8 & 22,7 & 27,6 & 29,4 & 33,5 & 40,4 \\
\hline Nordeste & 37,2 & 29,1 & 32,5 & 35,2 & 39,1 & 50,3 \\
\hline Sudeste & 36,6 & 24,8 & 30,6 & 34,1 & 38,1 & 54,3 \\
\hline Sul & 31,2 & 20,3 & 23,3 & 30,5 & 33,4 & 48,8 \\
\hline Centro-Oeste & 27,6 & 16,7 & 21,5 & 22,3 & 32.2 & 44,9 \\
\hline
\end{tabular}

Fonte: Pesquisa nacional por amostra de dorricilios 2001: microdados. Rio de Janeiro: IBGE, 2002. 1 CD-ROM. Nota: (1) Exclusive a população rural de Rondónia, Accre, Amazonas, Roraima, Pará e Amąąa.

(2) Exclusive a papulaçấo rural.

Tabela 9 - Taxa de escolarização de pessoas de 18 a 24 anos de idade, por quintos de rendimento mensal familiar per capita, segundo as Grandes Regióes - 2001

\begin{tabular}{|c|c|c|c|c|c|c|}
\hline \multirow{3}{*}{ Grandes Regiōes } & \multicolumn{6}{|c|}{ Taxa de escolarização de pessoas de 18 a 24 anos de idade (\%) } \\
\hline & \multirow{2}{*}{ Total } & \multicolumn{5}{|c|}{ Quintos de rendimento mensal familiar per capita } \\
\hline & & $1^{*}$ quinto & $2^{a}$ quinto & $3^{\circ}$ quinto & $4^{*}$ quinto & $5^{\circ}$ quinto \\
\hline Brasil (1) & 34,0 & 26,9 & 28,4 & 29,7 & 32,3 & 50,6 \\
\hline Norte (2) & 39,2 & 32,7 & 31,9 & 39,5 & 40,9 & 50,1 \\
\hline Nordeste & 37,5 & 27,6 & 33,0 & 36,2 & 38,8 & 50,1 \\
\hline Sudeste & 31,8 & 20,9 & 23,8 & 27,4 & 31,3 & 52,1 \\
\hline Sul & 31,2 & 18,7 & 20,6 & 26,1 & 32,6 & 56,4 \\
\hline Centro-Oeste & 33,6 & 23,4 & 24,7 & 32,5 & 33,7 & 53,1 \\
\hline
\end{tabular}

Fonte: Pesquisa nacional por amostra de domicilios 2001: microdadas. Rio de Janeiro: IBGE, 2002 1 CD-ROM.

Nota: (1) Exclusive a populaçāo rural de Rondónia, Acre, Amazonas, Roraima, Pará e Amạá.

(2) Exclusive a papulação rural. 
Tabela 10 - População ocupada, por cor ou raça, com indicação da média de anos de estudo e do rendimento médio mensal em salário mínimo, segundo as Grandes Regióes, Unidades da Federação e Regióes Metropolitanas - 2001

\begin{tabular}{|c|c|c|c|c|c|c|}
\hline \multirow[b]{3}{*}{$\begin{array}{l}\text { Grandes Regibes, } \\
\text { Unidades da Federaça e } \\
\text { Regibes Metropolitanas }\end{array}$} & \multicolumn{6}{|c|}{ Populaçăo ocupada, por cor ou raça } \\
\hline & \multicolumn{2}{|c|}{ Branca } & \multicolumn{2}{|c|}{ Preta } & \multicolumn{2}{|c|}{ Parda } \\
\hline & $\begin{array}{l}\text { Modia de } \\
\text { anos } \\
\text { de estudos }\end{array}$ & $\begin{array}{l}\text { Rendi: } \\
\text { mento } \\
\text { medio em } \\
\text { saliario } \\
\text { minimo }\end{array}$ & $\begin{array}{c}\text { Media de } \\
\text { anos } \\
\text { de estudos }\end{array}$ & $\begin{array}{l}\text { Rendi- } \\
\text { mento } \\
\text { medilo em } \\
\text { salario } \\
\text { minimo }\end{array}$ & $\begin{array}{c}\text { Media de } \\
\text { anos } \\
\text { de estudos }\end{array}$ & $\begin{array}{l}\text { Rendi- } \\
\text { mento } \\
\text { medio em } \\
\text { salario } \\
\text { minimo }\end{array}$ \\
\hline Brasil (1) & 8,0 & 4,50 & 5,7 & 2,20 & 5,6 & 2,20 \\
\hline Norte (2) & 8,0 & 4,20 & 5,7 & 2,50 & 6,4 & 2,50 \\
\hline Rondónia & 7,5 & 3,00 & 6.6 & 3,20 & 6,1 & 2,70 \\
\hline Acre & 7,8 & 5.80 & 5.6 & 4,40 & 6,4 & 3,30 \\
\hline Amazonas & 8,9 & 4,20 & 5,5 & 2,70 & 7,1 & 2,70 \\
\hline Roraima & 7,5 & 4,20 & 4.0 & 2,40 & 6,4 & 2,80 \\
\hline Pard & 7,7 & 3,90 & 5,8 & 2,20 & 6,1 & 2,20 \\
\hline Regiao Metropolitana de Beidem & 9,2 & 4,50 & 6.6 & 2,10 & 7,7 & 2,70 \\
\hline Amapá & 9,5 & 4,50 & 5.0 & 2,80 & 9,0 & 3,80 \\
\hline Tocartins & 7,0 & 4,50 & 3,9 & 2,00 & 5,4 & 2,00 \\
\hline Nordeste & 6,6 & 3,10 & 4,7 & 1,50 & 4,7 & 1,70 \\
\hline Maranhào & 5,8 & 2,80 & 4.6 & 1,40 & 4,4 & 1,70 \\
\hline Pisul & 6,1 & 2,70 & 4.2 & 1,70 & 4,2 & 1,50 \\
\hline Ceara & 6,5 & 2.80 & 4,4 & 1,90 & 4,5 & 1,00 \\
\hline Regiao Metropoltana de Fortaleza & 8,3 & 4.20 & 6,3 & 2,30 & 6,2 & 2,30 \\
\hline Rio Grande do Norte & 7,5 & 3,30 & 4.8 & 1,60 & 5,3 & 1,90 \\
\hline Parabo & 6,7 & 3,00 & 3,3 & 1,30 & 4,3 & 1,60 \\
\hline Pemambuco & 7,1 & 3,40 & 4,5 & 1,50 & 5,0 & 1,70 \\
\hline Regiao Metropolitana de Recife & 92 & 5,00 & 6.0 & 1,90 & 6,9 & 2,30 \\
\hline Alagoas & 6,3 & 3,10 & 3.5 & 1,40 & 3,7 & 1,40 \\
\hline Sergipe & 7.6 & 3,30 & 6.4 & 1,90 & 5,0 & 1,80 \\
\hline Bahia & 6,1 & 3.20 & 4,9 & 1,60 & 4,9 & 1,70 \\
\hline Regia Metropolitana de Salvador & 10,3 & 7,20 & 6.8 & 2,10 & 7,6 & 2,70 \\
\hline Sudeste & 8,5 & 5,10 & 6,1 & 2,50 & 6,4 & 2,60 \\
\hline Minas Gerais & 7.6 & 3,70 & 5.0 & 1,80 & 5,8 & 2,20 \\
\hline Regiao Metropoltana de Belo Horizonte & 9,0 & 4.80 & 6,3 & 2,60 & 7,2 & 2,90 \\
\hline Espirito Santo & 7,9 & 4,20 & 4,9 & 1,80 & 6,4 & 2,50 \\
\hline Rio de Janeiro & 9,0 & 5,40 & 6.3 & 2,30 & 6,8 & 2,80 \\
\hline Regiao Metropoltana do Rio de Janeiro & 9.4 & 5,50 & 6.6 & 2,50 & 7,1 & 2,90 \\
\hline Sลa Paulo & 8.6 & 5,50 & 6.8 & 3,30 & 6,7 & 2,90 \\
\hline Regia Metropoltana de Sa Paulo & 92 & 6,40 & 7,0 & 3,60 & 7,0 & 3,10 \\
\hline Sul & 7,6 & 3,90 & 6,1 & 2,40 & 5,5 & 2,30 \\
\hline Parand & 7,7 & 4,00 & 5,4 & 2,30 & 5,4 & 2,40 \\
\hline Regiao Metropoltana de Curisba & 8,5 & 5,10 & 6,5 & 2,80 & 5,8 & 2,60 \\
\hline Santa Catarina & 7,7 & 3,80 & 6.2 & 2,70 & 5,8 & 2,20 \\
\hline Riu Grante utu 3ul & 7,0 & 4,00 & 6.4 & 2,30 & D,8 & 2,10 \\
\hline Regiaso Metropoltana de Porto Alegre & 8,5 & 4,90 & 70 & 2,50 & 6,2 & 2,80 \\
\hline Centro-Oeste & 8,1 & 5,10 & 5,8 & 2,80 & 6,2 & 2,70 \\
\hline Mato Grosso do Sul & 7,7 & 4,30 & 5.8 & 3,10 & 5,9 & 2,30 \\
\hline Mato Groaso & 7,7 & 4,80 & 5.6 & 2,80 & 5,7 & 2,70 \\
\hline Gaids & 7,6 & 4,10 & 5,1 & 1,90 & 5,9 & 2,30 \\
\hline Distribo Federal & 10,1 & 8.70 & 7,2 & 4,10 & 7,9 & 4,40 \\
\hline
\end{tabular}

Fonte: Pesquisa nacional por amestra de domicillos 2001: microdados. Rio de Janeino IBGE, 2002. 1 CD-ROM. Nota: Compreendem as pessoas de 10 anos ou mais de idade.

(1) Exclusive a populaçso rural de Rondónia, Acre, Amazonas, Roraima, Pard e Amapa.

(2) Exclusive a populaçso rural. 
Tabela 11 - Crianças e adolescentes de 5 a 17 anos de idade residentes em domicílios particulares, total e sua respectiva distribuição percentual, por condição de ocupação e classes de rendimento médio mensal familiar per capita, em salário mínimo, segundo as Grandes Regiões, Unidades da Federação e

Regióes Metropolitanas - 2001

\begin{tabular}{|c|c|c|c|c|c|c|}
\hline \multirow{3}{*}{$\begin{array}{l}\text { Grandes Regiees, } \\
\text { Unidades da Foderação e } \\
\text { Regioes Metropolitanas }\end{array}$} & \multirow{3}{*}{ Total } & \multicolumn{5}{|c|}{$\begin{array}{l}\text { Crianģas e adolescentes de } 5 \text { a } 17 \text { anos de idade, por } \\
\text { condiça de ocupaçaso e classes de rendimento médio } \\
\text { mensal tamiliar per capita em salário minimo }\end{array}$} \\
\hline & & \multicolumn{5}{|c|}{ Ocupados (\%) } \\
\hline & & Ate $1 / 4$ & $\begin{array}{c}\text { Do } \\
1 / 4 \mathrm{a}_{1 / 2}\end{array}$ & $\begin{array}{c}\text { De } \\
1 / 2 \text { a } 1\end{array}$ & $\begin{array}{c}\text { De } \\
1 \text { a } 2\end{array}$ & $\begin{array}{c}\text { Mais } \\
\text { de } 2\end{array}$ \\
\hline Brasil (1) & 5421773 & 24,9 & 22,9 & 24,9 & 15,8 & 8,2 \\
\hline Norte (2) & 246062 & 13,1 & 28,2 & 34,4 & 15,4 & 6,7 \\
\hline Rondoria & 20639 & 40 & 19,8 & 42.6 & 21,8 & 10,9 \\
\hline Aur & 11 saz & 14,0 & 28,1 & 24,4 & 13,4 & 3.8 \\
\hline Amazonas & 40617 & 18,6 & 29,3 & 32.1 & 14,3 & 2,9 \\
\hline Roraims & 4463 & 15,4 & 19,2 & 23,1 & 19,2 & 23,1 \\
\hline Pard & 128314 & 14,1 & 31,6 & 33,4 & 13,1 & 6,2 \\
\hline Regiao Metropolitana de Beiém & 23665 & 11,2 & 23,0 & 34.2 & 17,1 & 9,2 \\
\hline Amapá & 3411 & 14,3 & 21,5 & 80.0 & 7,1 & 7,2 \\
\hline Tocartins & 61134 & 27.2 & 21,4 & 32,1 & 13,4 & 4.8 \\
\hline Nordeste & 2304745 & 41,5 & 29,6 & 18,9 & 4,6 & 1,7 \\
\hline Maranhão & 414246 & 46,1 & 27,6 & 19,9 & 2,6 & 2,2 \\
\hline Pisul & $137 \$ 44$ & 43,0 & 28,1 & 18.6 & 4,2 & 0,8 \\
\hline Ceara & 366284 & 40,2 & 30,1 & 19,5 & 4,9 & 1,9 \\
\hline Regiao Metropaltana de Fortaleza & 79514 & 19,0 & 29,6 & 27.8 & 13,8 & 6,9 \\
\hline Rio Grande do Norte & 87677 & 37,4 & 26,8 & 25,7 & 6,7 & 2,8 \\
\hline Parabo & 129110 & 42,9 & 31,8 & 15,4 & 7,5 & 1,1 \\
\hline Pemambuco & 359120 & 44,7 & 27,1 & 17,4 & 5,6 & 1,4 \\
\hline Regiao Metropolitana de Fecife & 50379 & 17,7 & 26,5 & 34,5 & 12,2 & 5.0 \\
\hline Alagoas & 141756 & 47,7 & 30,2 & 15,4 & 5,4 & 1,3 \\
\hline Sergipe & 62610 & 29,6 & 37,1 & 18.8 & 8,1 & 1,6 \\
\hline Bahia & 607399 & 37,1 & 31,3 & 192 & 3,8 & 1,7 \\
\hline Regiao Metropolitana de Salvsdor & 59121 & 11,4 & 35,0 & 34.6 & 12,1 & 3,9 \\
\hline Sudeste & 1570142 & 10,4 & 16,9 & 28,6 & 25,4 & 14.9 \\
\hline Minas Geras & 572353 & 18,2 & 23,0 & 29,7 & 18,6 & 7,6 \\
\hline Regiao Metropoltana de Bela Horizonte & 82406 & 10,9 & 11,4 & 35,4 & 31,0 & 8,7 \\
\hline Espirito Santo & $107 \$ 40$ & 15,5 & 29,8 & 31.5 & 13,0 & 6,7 \\
\hline Fio de Janeiro & 147466 & 7,0 & 14,7 & 33.8 & 26,7 & 13,9 \\
\hline Regiao Metropolitana do Fio de Janeiro & 86112 & 6,3 & 9,9 & 31,7 & 33,1 & 14.8 \\
\hline Săo Paulo & 742783 & 4.4 & 10,7 & 26.4 & 32,1 & 22.0 \\
\hline Regiao Metropolitana de Sao Paulo & 306789 & 5,9 & 8,1 & 21,8 & 31,0 & 26,0 \\
\hline Sul & 916651 & 15,5 & 17,3 & 28,4 & 24,4 & 12,5 \\
\hline Parand & 347660 & 20,5 & 19,0 & 28.7 & 19,9 & 10,4 \\
\hline Regia Metropaltana de Curitba & 64490 & 4,5 & 14,1 & 260 & 34,5 & 19.8 \\
\hline Santa Catarina & 206170 & 9,2 & 9,7 & 28.9 & 30,8 & 18.6 \\
\hline Rio Grande do Sul & 363821 & 14,3 & 19,9 & 27,9 & 25,1 & 11,0 \\
\hline Regiao Metropolitana de Porio Alegre & 75049 & 3,9 & 12,9 & 23,7 & 36,4 & 20,1 \\
\hline Centro-Oeste & 359794 & 10,9 & 17,9 & 32.8 & 25,9 & 10,7 \\
\hline Mato Grosso do Sul & 64179 & 10,9 & 13,4 & 36,3 & 27,9 & 9,9 \\
\hline Mato Grosso & 104501 & 15,4 & 20,0 & 27.2 & 24,9 & 9.8 \\
\hline Gaisa & 168688 & 9,3 & 18,5 & 360 & 25,1 & 9.7 \\
\hline Distribo Federal & 22066 & 1.8 & 16,1 & 250 & 30,4 & 24,1 \\
\hline
\end{tabular}

Fonte: Pesquisa nacional por amostra de domicilos 2001: microdados. Rio de Janeiro: IBGE, 2002. 1 CD-ROM.

Nota: (1) Exclusive a populaçso rural de Roondonia, Acre, Amszonas, Rorama, Para e Amapd.

(2) Exclusive a populap̧so rural. 
Tabela 12 - Média de anos de estudo da população de 25 anos ou mais de idade, por quintos de rendimento mensal familiar per capita, segundo as Grandes Regióes,

Unidades da Federação e Regiões Metropolitanas - 2001

\begin{tabular}{|c|c|c|c|c|c|}
\hline \multirow{2}{*}{$\begin{array}{l}\text { Grandes Regiōes, } \\
\text { Unidades da Federação e } \\
\text { Regiōes Metropolitanas }\end{array}$} & \multicolumn{5}{|c|}{$\begin{array}{l}\text { Média de anos de estudo da população de } 25 \text { anos ou mais de } \\
\text { idade, por quintos de rendimento mensal familiar per capita }\end{array}$} \\
\hline & $1^{\circ}$ quinto & $z^{2}$ quinto & $3^{\circ}$ quinto & $4^{2}$ quinto & $5^{\circ}$ quinto \\
\hline Brasil (1) & 4,4 & 5,4 & 6,0 & 7,9 & 11,1 \\
\hline Norte (2) & 5,2 & 6,1 & 6,9 & 8,7 & 11,3 \\
\hline Rondônia & 4,6 & 5,1 & 6,2 & 7.7 & 11,3 \\
\hline Acre & 4,0 & 5,8 & 5,9 & 8,3 & 10,9 \\
\hline Amazonas & 5,8 & 6,8 & 7,8 & 9,5 & 11,3 \\
\hline Roraima & 4,7 & 5,3 & 5,7 & 7,5 & 10,4 \\
\hline Pará & 5,3 & 6,1 & 6,8 & 8,6 & 11,4 \\
\hline Regiâo Metrapoltana de Belém & B,7 & 7,6 & 8,1 & 9,4 & 12,4 \\
\hline Amapa & $b, y$ & 7,2 & 7,4 & $y, 1$ & 11,6 \\
\hline Tocantins & 3,9 & 4,8 & 5,7 & 8,3 & 10,7 \\
\hline Nordeste & 3,8 & 4,8 & 5,6 & 8,5 & 11,4 \\
\hline Maranhão & 4,1 & 4,7 & 5,8 & 8,1 & 9,9 \\
\hline Piauí & 3,3 & 4,5 & 5,3 & 8.2 & 10,7 \\
\hline Ceará & 3.8 & 4,9 & 5,8 & 8,7 & 11,7 \\
\hline Regiâo Metropoittana de Fortaleza & 5,3 & 6,3 & 7,5 & 9,2 & 12,0 \\
\hline Ria Grande do Norte & 4,1 & 5,1 & 6,1 & 8,8 & 11,8 \\
\hline Paraiba & 3.6 & 4,6 & 4,8 & 9,2 & 11,8 \\
\hline Pemambuco & 4,1 & 5,0 & 5,9 & 8,7 & 11,8 \\
\hline Regiâo Metropolitana de Recife & 5,7 & 6,3 & 7,2 & 9,2 & 12,2 \\
\hline Nagoas & 3,4 & 4,6 & 6,2 & 8,4 & 11,4 \\
\hline Sergipe & 42 & 5,6 & 6,1 & B, 7 & 11,2 \\
\hline Bahia & 3,6 & 4,7 & 6,3 & 8,4 & 11,3 \\
\hline Regiâo Metropolitana de Salvador & 6.2 & 6,9 & 7,4 & 9,7 & 12,0 \\
\hline Sudeste & 5.2 & 5,7 & 6,2 & 7,8 & 11,1 \\
\hline Minas Gerais & 4,4 & 5,3 & 5,8 & 8,0 & 11,2 \\
\hline Regiâo Metrapoittana de Belo Horizonte & 5,9 & 6,2 & 6,5 & 8,4 & 11,8 \\
\hline Espinito Santo & 5.0 & 5,4 & 6,0 & 8,1 & 11,2 \\
\hline Ria de Janeira & 5,8 & 6,3 & 6,5 & 8,1 & 11,4 \\
\hline Regiâo Metrapoitana do Rio de Janeiro & B.2 2 & 6,5 & 6,7 & 8.2 & 11,4 \\
\hline São Paulo & 5,6 & 5,7 & 6,2 & 7,6 & 11,0 \\
\hline Regiâo Metrapoitana de São Paulo & 6.0 & 6,0 & 6,6 & 7,7 & 11,0 \\
\hline Sul & 4,9 & 5,6 & 6,1 & 7,7 & 10,9 \\
\hline Paraná & 4,5 & 5,4 & 6,0 & 7.8 & 11,2 \\
\hline Regiâo Metrapoltana de Curitiba & 5.5 & 5,9 & 6,5 & 8,1 & 11,5 \\
\hline Santa Catarina & 5.2 & 5,7 & 6,2 & 7,6 & 10,6 \\
\hline Rio Grande do Sul & 5.2 & 5,7 & 6,1 & 7,6 & 10,9 \\
\hline Regiâo Metropolitana de Porto Alegre & 6.2 2 & 6,1 & 6,8 & 8,0 & 11,4 \\
\hline Centro-Oeste & 4,9 & 5,4 & 5,9 & 7,9 & 11,3 \\
\hline Mato Grosso do Sul & 4,7 & 5,6 & 5,8 & 8.0 & 11,2 \\
\hline Mato Grosso & 4,3 & 5,0 & 5,6 & 7.6 & 10,7 \\
\hline Goiás & 4,9 & 5,4 & 6,8 & 7,7 & 10,9 \\
\hline Distrito Federal & 6.3 & 6,2 & 7,6 & 8.8 & 12,1 \\
\hline
\end{tabular}

Fonte: Pesquisa nacional por amostra de domicilios 2001: microdados. Rio de Janeiro: IBGE, 2002. 1 CD-ROM.

Nota: (1) Exclusive a populaçāo rural de Rondönia, Acre, Amazonas, Raraima, Pará e Amapá.

(2) Exclusive a população rural. 
Tabela 13 - Média de anos de estudo da população de 10 anos ou mais de idade, total e ocupada, por sexo, segundo as Grandes Regióes, Unidades da

Federação e Regiões Metropolitanas - 2001

\begin{tabular}{|c|c|c|c|c|c|c|}
\hline \multirow{3}{*}{$\begin{array}{l}\text { Grandes Regides, } \\
\text { Unidades da Federaçăe e } \\
\text { Regioes Metropolitanas }\end{array}$} & \multicolumn{6}{|c|}{$\begin{array}{l}\text { Médila de anos de estudo da populaça do de } 10 \text { anos ou mais de idade, } \\
\text { por sexo }\end{array}$} \\
\hline & \multicolumn{3}{|c|}{ Total } & \multicolumn{3}{|c|}{ Ocupada } \\
\hline & Total & Homens & Mulheres & Total & Homens & Mulheres \\
\hline Brasil (1) & 6,1 & 5,9 & 6,2 & 6,7 & 6,3 & 7,3 \\
\hline Norte (2) & 6,0 & 5,8 & 6,2 & 6,7 & 6,3 & 7,5 \\
\hline Rendoria & 5,8 & 5,7 & 5,8 & 6,6 & 6,1 & 7,4 \\
\hline Acre & 5.8 & 5,7 & 6,0 & 6,5 & 6,2 & 7,0 \\
\hline Amazonas & 6,4 & 6,3 & 6,5 & 7,5 & 7,1 & 8,1 \\
\hline Roraima & 5,7 & 5,6 & 5,9 & 6,4 & 5,9 & 7,2 \\
\hline Pará & 5.8 & 5,6 & 6,0 & 6,4 & 5,9 & 7,2 \\
\hline Regias Motropolitana de Delem & 7,1 & 7,0 & 7,2 & $a, 0$ & 7,7 & e, 5 \\
\hline Amapa & 7,3 & 7,3 & 7,3 & 8.6 & 8,3 & 9,3 \\
\hline Tocartins & 5,1 & 4,7 & 5,6 & 5,5 & 4,9 & 6,5 \\
\hline Nordeste & 4,7 & 4,3 & 5,0 & 4,9 & 4,4 & 5,8 \\
\hline Maranhso & 4,4 & 4,0 & 4,7 & 4,3 & 3,8 & 4,9 \\
\hline Pisul & 4.2 & 3,7 & 4,6 & 4,3 & 3,7 & 5,3 \\
\hline Ceara & 4.8 & 4,4 & 5,1 & 5,0 & 4,4 & 5,8 \\
\hline Regiano Metropoltana de Fortaleza & 6.3 & 6,1 & 6,6 & 7.0 & 6,5 & 7,6 \\
\hline Rio Grande do Norte & 5,2 & 4,8 & 5,6 & 5,9 & 5,2 & 7,1 \\
\hline Parabo & 4,4 & 3,9 & 4,8 & 4,9 & 4,1 & 6,2 \\
\hline Pemambuco & S,1 & 4,8 & 5,4 & 5,5 & 5,0 & 6,2 \\
\hline Regiaso Metropolitana de Recife & 6.6 & 6,5 & 6,8 & 7,8 & 7,3 & 8,4 \\
\hline Alsgoas & 4,0 & 3,7 & 4,3 & 4,2 & 3,6 & 5,0 \\
\hline S̈ergipe & 3,1 & 4,6 & 5,4 & 5,4 & 4,8 & 6,3 \\
\hline Bahis & 4.6 & 4,3 & 4,9 & 4,9 & 4,4 & 5,7 \\
\hline Regia Metropoltana de Salvador & 7,1 & 7,0 & 7,1 & 7,9 & 7,6 & 8,3 \\
\hline Sudeste & 6,8 & 6,8 & 6,8 & 7,7 & 7,4 & 8,2 \\
\hline Minas Geras & 6.0 & 5,8 & 6,1 & 6,5 & 6,1 & 7,1 \\
\hline Regiāo Metropoltana de Belo Horizonte & 7,1 & 7,1 & 7,2 & 8,0 & 7,7 & 8,5 \\
\hline Esplitiso Santo & 6.2 & 6,0 & 6,3 & 6.8 & 6,4 & 7,3 \\
\hline Rio de Janeiro & 7,1 & 7,1 & 7,1 & 8,1 & 7,8 & 8,6 \\
\hline Regiào Metropoltana do Fio de Janeiro & 7,4 & 7,4 & 7,3 & 8,5 & 8,3 & 8,8 \\
\hline Sao Paulo & 7,1 & 7,1 & 7,1 & 8,2 & 7,9 & 8,7 \\
\hline Regiáo Metropoltana de Sao Paulo & 7,4 & 7,5 & 7,4 & 8,6 & 8,3 & 9,0 \\
\hline Sul & 6,5 & 6,4 & 6,5 & 7,1 & 6,8 & 7,5 \\
\hline Parand & 6.3 & 6.3 & 6.4 & 7.0 & 6.8 & 7.4 \\
\hline Regia Metropoltana de Curnba & 7,2 & 7,3 & 7,1 & 8,0 & 7,9 & 8,2 \\
\hline Santa Catarina & 6.6 & 6,6 & 6,7 & 7,3 & 7,1 & 7,6 \\
\hline Rio Grande do Sul & 6.6 & 6,4 & 6,7 & 7,1 & 6,8 & 7,5 \\
\hline Regia Metropoltana de Porto Alogre & 7,3 & 7,3 & 7,3 & 8,2 & 7,9 & 8,6 \\
\hline Centro-Qeste & 6.2 & 6,0 & 6,4 & 6,9 & 6,4 & 7,6 \\
\hline Mato Grosso do Sul & 6,1 & 6,0 & 6,2 & 6.8 & 6,4 & 7,4 \\
\hline Mato Groseo & 5,7 & 5,5 & 6,0 & 6.2 & 5,7 & 7,2 \\
\hline Goiss & 5.9 & 5,6 & 6,1 & 6,5 & 6,1 & 7,2 \\
\hline Distribo Federal & 7,8 & 7,7 & 7,9 & 8,9 & 8,5 & 9,3 \\
\hline
\end{tabular}

Fonte: Pesquisa nacianal por amestra de domicilias 2001: micrododos. Foo de Janeiro: IBGE, 2002. 1 CD-RCM. Notax (1) Exclusive a populaçso rural de Rondónia, Acre, Amazonas, Roraima, Pard e Amapa.

(2) Exclusive a populaçso rural. 
Tabela 14 - Proporção da população ocupada que contribui e não contribui para a previdência social, por sexo, segundo as Grandes Regióes, Unidades da

Federação e Regióes Metropolitanas - 2001

\begin{tabular}{|c|c|c|c|c|c|c|}
\hline \multirow{3}{*}{$\begin{array}{l}\text { Grandes Regibes, } \\
\text { Unidades de Federaça e } \\
\text { Regioes Metropolitanas }\end{array}$} & \multicolumn{6}{|c|}{$\begin{array}{l}\text { Proporça da populaça ocupada que contribul e } \\
\text { nso contribui para a previdência social, por sexo (\%) }\end{array}$} \\
\hline & \multicolumn{3}{|c|}{ Contribul } & \multicolumn{3}{|c|}{ NSo contribui } \\
\hline & Total (1) & Homens & Mulheres & Total (1) & Homens & Mulheres \\
\hline Brasil (2) & 45,7 & 46,1 & 45,1 & 54,3 & 53,9 & 54,9 \\
\hline Norte (3) & 38,6 & 37,8 & 39,9 & 61,3 & 62,2 & 60,1 \\
\hline Randonia & 45,4 & 44,0 & 48,0 & 84.6 & 56,0 & $\$ 20$ \\
\hline Acre & 44,3 & 43,2 & 45,8 & $B 5,7$ & 56,8 & 54,2 \\
\hline Amazonas & 44.5 & 43,5 & 46.0 & SOS.5 & 56,5 & 840 \\
\hline Raraima & 35.8 & 31,2 & 43,1 & 642 & 68,8 & $\infty 6,9$ \\
\hline Part & 33.6 & 33,5 & 33,8 & 66,4 & 66,5 & 66.2 \\
\hline Regiso Motropoltana de Belém & 43,7 & 43,9 & 43,3 & 86,3 & 56,1 & 86,7 \\
\hline Amapd & 86.1 & 55.0 & 88,7 & 43.9 & 45,0 & 41,3 \\
\hline Tocantins & 27,0 & 23,8 & 32,3 & 730 & 76,2 & 67,7 \\
\hline Nordeste & 27,7 & 26,6 & 29,3 & 72,3 & 73,4 & 70,7 \\
\hline Moranhäo & 18.6 & 17,9 & 19,7 & 81,4 & 82,1 & 80,3 \\
\hline Piaui & 19.5 & 16.6 & 24,1 & 80.5 & 83,4 & 75,9 \\
\hline Ceara & 25,3 & 24,8 & 25,8 & 74,7 & 75,1 & 74.2 \\
\hline Regiso Metropoltana de Fortaleza & 41,8 & 43,9 & 39,0 & 88.2 & 56,1 & 61,0 \\
\hline Rio Grande do Narte & 36.5 & 32,9 & 420 & 63.5 & 67,1 & $\$ 80$ \\
\hline Paralba & 32.6 & 29,7 & 37,3 & 67,4 & 70,3 & 62,7 \\
\hline Pernambudo & 32.2 & 32,5 & 31,7 & 67,8 & 67,5 & 68,3 \\
\hline Regiso Metropelitana de Recife & 49.8 & 80,9 & 48,5 & 50.2 & 49,1 & 51,5 \\
\hline Alagoas & 28.8 & 28,0 & 30,1 & 71.2 & 72,0 & 699 \\
\hline Sergipe & 37,1 & 35,6 & 39,4 & 629 & 64,4 & 60,6 \\
\hline Eahia & 28,1 & 27,0 & 29,7 & 71.9 & 73,0 & 70,3 \\
\hline Regiso Motropoltana de Salvadar & 52.8 & 54.8 & $s 0,1$ & 47,2 & 45,2 & 49,9 \\
\hline Sudeste & 56,7 & 58,0 & 54,7 & 43,3 & 42,0 & 45,3 \\
\hline Mnas Gerais & 46.8 & 48,1 & 44.8 & 83.2 & 51,8 & 85,2 \\
\hline Regiso Metropoltana de Belo Horizonte & 61,0 & 62,5 & 890 & 390 & 37,5 & 41,0 \\
\hline Espinto Santo & 44,3 & 45,8 & 42.2 & B5,7 & 54,2 & 57.8 \\
\hline Rio de Janeiro & 589 & 89,7 & 57.9 & 41.0 & 40,3 & 42,1 \\
\hline Regiso Metropoltana do Rio de Janeiro & 60,3 & 61,0 & 89,3 & 39,7 & 38,9 & 40,7 \\
\hline Saso Paulo & 61.8 & 63,4 & 69,5 & 38.2 & 36,6 & 40,5 \\
\hline Regiso Metropoltana de SSo Paulo & 62,1 & 63,7 & 60.0 & 37,9 & 36,3 & 40,0 \\
\hline Sul & 49,8 & 51,5 & 47,5 & 50.2 & 48,5 & 52,5 \\
\hline Parana & 46,4 & 48,2 & 43.8 & 83.6 & 51,8 & 86,2 \\
\hline Regiso Metropoltana de Curitiba & 580 & 89,9 & S5,4 & 420 & 40,1 & 44.6 \\
\hline \multirow[t]{2}{*}{ Santa Catarina } & 56.2 & $\$ 8,1$ & $\$ 3.6$ & 43.8 & 41,9 & 46,4 \\
\hline & 49,4 & $\$ 0,9$ & 47,5 & 50.6 & 49,1 & 52.5 \\
\hline Regiso Metropoitana de Porto Alegre & 62.4 & 62,8 & 61,9 & 37.6 & 37,1 & 38,1 \\
\hline Centro-Oeste & 44,3 & 44,7 & 43,8 & 55,7 & 55,3 & 56,2 \\
\hline Maso Grosso do Sul & 44.5 & 45,9 & 422 & BS.5 & 54,1 & 57.8 \\
\hline Moso Grosso & 38.0 & 38,6 & 36.8 & 620 & 61,4 & 632 \\
\hline Goias & 40,5 & 41,4 & 39,3 & 89.5 & 58,6 & 60,7 \\
\hline Distrits Federal & 62.9 & 62.6 & 63.3 & 37,1 & 37,4 & 36.7 \\
\hline
\end{tabular}

Fonte: Pesquisa nacional por amostra de domicilos 2001: microdados. Rio de Janeiro: IBGE, 2002. 1 CD-ROM. Nota: 1. Compreendem as pessoas de 10 anos e mais de idade.

2. Contribuição para instituto de previdéncia em qualquer trabalho.

(1) Inclusive trabalhadores na produçăo para o próprio consumo, trabalhadores na construçẫo para próprio uso e sem declaraça.

(2) Exclusive a populaçào rural de Rondônia, Acre, Amazonas, Roraima, Pará e Amapd́.

(3) Exclusive a populaçăo rural. 
Tabela 15 - Rendimento-hora da população ocupada, em reais, por grupos de anos de estudo, segundo as Grandes Regiões, Unidades da Federação e

Regiões Metropolitanas - 2001

\begin{tabular}{|c|c|c|c|c|c|}
\hline \multirow{3}{*}{$\begin{array}{l}\text { Grandes Regiōes, } \\
\text { Unidades de Federação e } \\
\text { Regiōes Metropolitanas }\end{array}$} & \multicolumn{5}{|c|}{ Rendimento-hora da população ocupada } \\
\hline & \multirow{2}{*}{ Total } & \multicolumn{4}{|c|}{ Grupos de anos de estudo } \\
\hline & & Até 4 anos & $\begin{array}{c}\text { De } 5 \text { a } 8 \\
\text { anos }\end{array}$ & $\begin{array}{c}\text { De } 9 \text { a } 11 \\
\text { anos }\end{array}$ & $\begin{array}{c}\text { Mais de } 12 \\
\text { anos }\end{array}$ \\
\hline Brasil (1) & 3,70 & 1,90 & 2,50 & 3,90 & 11,30 \\
\hline Norte (2) & 3,30 & 1,80 & 2,20 & 3,70 & 12,10 \\
\hline Rondōnia & 3,30 & 1,90 & 2,50 & 3,90 & 10,10 \\
\hline Acre & 4,40 & 1,90 & 2,90 & 4,90 & 13.20 \\
\hline Amazonas & 3,80 & 1,80 & 2,20 & 3,40 & 17,10 \\
\hline Roraima & 3,60 & 2,30 & 3,20 & 3,90 & 11,70 \\
\hline Pará & 3,00 & 1,80 & 2,00 & 3,70 & 10,60 \\
\hline Região Metropolitana de Belém & 3,80 & 2.20 & 2,00 & 3,90 & 11,70 \\
\hline Amapá & 3,90 & 2,50 & 3,00 & 3,80 & 9,00 \\
\hline Tocantins & 3,00 & 1,90 & 2,20 & 3,80 & 10,60 \\
\hline Nordeste & 2,30 & 1,20 & 1,80 & 3,10 & 9,40 \\
\hline Maranhão & 2,20 & 1,60 & 1,60 & 3,20 & 8,00 \\
\hline Piaui & 1,90 & 0,90 & 1,40 & 3,40 & 6,40 \\
\hline Ceará & 2,20 & 1,00 & 1,70 & 2,80 & 9,90 \\
\hline Região Metropolitana de Fortaleza & 3,30 & 1,40 & 2,10 & 3,20 & 12,10 \\
\hline Rio Grande do Norte & 2,70 & 1,30 & 2,00 & 3,00 & 9,50 \\
\hline Paraiba & 2,50 & 1,10 & 1,60 & 2,70 & 10,50 \\
\hline Pemambuco & 2,50 & 1,20 & 1,80 & 2,90 & 9,40 \\
\hline Região Metropolitana de Recife & 3,50 & 1,40 & 1,90 & 3,20 & 10,90 \\
\hline Alagoas & 2,20 & 1,20 & 1,90 & 3,10 & 9,30 \\
\hline Sergipe & 2,30 & 1,40 & 1,70 & 2,80 & 8.20 \\
\hline Bahia & 2,30 & 1,20 & 1,80 & 3,30 & 10,30 \\
\hline Região Metropolitana de Salvador & 3,70 & 1,50 & 1,80 & 3,90 & 12,10 \\
\hline Sudeste & 4,40 & 2,30 & 2,80 & 4,20 & 12,20 \\
\hline Minas Gerais & 3,10 & 1,80 & 2,20 & 3,30 & 9,50 \\
\hline Região Metropolitana de Belo Horizonte & 4,00 & 2,10 & 2,40 & 3,90 & 11,50 \\
\hline Eapirito Eanto & 3,30 & 1,70 & 2,10 & 3,70 & 10,80 \\
\hline Rio de Janeiro & 4,50 & 2.20 & 2,70 & 4,20 & 11,80 \\
\hline Região Metropolitana do Rio de Janeiro & 4,90 & 2,30 & 2,90 & 4,50 & 12,30 \\
\hline Sảo Paulo & 5,10 & 2,70 & 3,20 & 4,60 & 13,10 \\
\hline Região Metropolitana de São Paulo & 5,90 & 3,00 & 3,40 & 4,80 & 14,70 \\
\hline Sul & 3,80 & 2,20 & 2,70 & 4,00 & 9,60 \\
\hline Paraná & 3,70 & 2.20 & 2,60 & 3,70 & 9,50 \\
\hline Região Metropolitana de Curitioa & 4,80 & 2,50 & 3,00 & 4,40 & 11,30 \\
\hline Santa Catarina & 3,80 & 2,50 & 2,90 & 3,90 & 8.80 \\
\hline Rio Grande do Sul & 3,90 & 2,00 & 2,60 & 4,40 & 10,10 \\
\hline Região Metropolitana de Porto Alegre & 4,70 & 2.20 & 2,80 & 4,50 & 11,80 \\
\hline Centro-Oeste & 4,00 & 2,10 & 2,60 & 4,20 & 12,40 \\
\hline Mato Grosso do Sul & 3,50 & 2,10 & 2,40 & 3,70 & 10,00 \\
\hline Mato Grosso & 3,60 & 2,30 & 2,60 & 4,30 & 10,10 \\
\hline Goiàs & 3,30 & 2,00 & 2,30 & 3,60 & 10,90 \\
\hline Distrilto Federal & 6,80 & 2.40 & 3,50 & 5,50 & 16.90 \\
\hline
\end{tabular}

Fonte: Pesquisa nacional por amostra de domicilios 2001: microdados. Rio de Janeiro: IBGE, 2002. 1 CD-ROM.

Notas: 1. Rendimento semanal de todos $\mathrm{De}$ trabalhas das pessoas ocupadas de 10 anas e mais de idade corm rendimento.

2. Exclusive sem declaraçâa de anos de estudo e horas trabalhadas.

(1) Exclusive a populaçăo rural de Rondônia, Acre, Amazonas, Roraima, Pará e Amapá.

(2) Exclusive a populaçāo rural. 
Tabela 16 - Domicílios particulares permanentes urbanos, total e proporção dos domicílios com abastecimento de água e esgotamento sanitário adequado e lixo coletado, por classes de rendimento médio mensal domiciliar per capita em salário mínimo, segundo as Grandes Regiões, Unidades da Federação e

Regiões Metropolitanas - 2001

\begin{tabular}{|c|c|c|c|c|c|c|c|c|}
\hline \multirow{4}{*}{$\begin{array}{l}\text { Grandes Regioes, } \\
\text { Unidades da Federaçso e } \\
\text { Regices Motropolitanas }\end{array}$} & \multicolumn{8}{|c|}{ Domicilios particulares permanentes urbanos } \\
\hline & \multirow{3}{*}{$\begin{array}{c}\text { Total } \\
\text { (1) }\end{array}$} & \multicolumn{7}{|c|}{$\begin{array}{l}\text { Com abastecimento de água e esgotamento sanitario } \\
\text { adequado e lixo coletado }\end{array}$} \\
\hline & & \multirow{2}{*}{$\begin{array}{l}\text { Total } \\
\text { (\$) }\end{array}$} & \multicolumn{6}{|c|}{$\begin{array}{l}\text { Classes de rendimento módio mensal domiciliai } \\
\text { per capita em salario minimo ( } \mathrm{\psi})\end{array}$} \\
\hline & & & Ate $1 / 2$ & $\begin{array}{c}\text { Mals } \\
\text { de } \\
1 / 2 \text { a } 1\end{array}$ & $\begin{array}{l}\text { Mais } \\
\text { de } \\
1 \text { a } 2\end{array}$ & $\begin{array}{l}\text { Mais } \\
\text { de } \\
2 \text { a } 3\end{array}$ & $\begin{array}{l}\text { Mals } \\
\text { de } \\
3 \text { a } 5\end{array}$ & $\begin{array}{l}\text { Mais } \\
\text { de } 5\end{array}$ \\
\hline Brasil & 39613032 & 62.2 & 38,2 & 53,4 & 66,8 & 75,7 & 81,0 & 86,1 \\
\hline Norte & 2263971 & 11,3 & 7,0 & 8,6 & 11,7 & 15,9 & 24,9 & 30,0 \\
\hline Rondoria & 239945 & 27 & 1,8 & 1,4 & 1.4 & 5,7 & 10,0 & 9,1 \\
\hline Acre & 95165 & 24,5 & 12,8 & 19,2 & 31.6 & 26,9 & 44,2 & 40,7 \\
\hline Amazonas & 494092 & 11,3 & 6,7 & 9,9 & 14.6 & 12,9 & 24,7 & 17,4 \\
\hline Roraims & 64360 & 14.9 & 13,4 & 11,8 & 9.8 & 21,9 & 29,1 & 23,5 \\
\hline Para & 1015100 & 13.5 & 7,8 & 10,5 & 14,1 & 21,8 & 32,2 & 44,4 \\
\hline Regiao Metropolitana de Belém & 436641 & 28,4 & 18,1 & 22,9 & 26.8 & 42,6 & 53,6 & 62,7 \\
\hline Amapá & 126035 & 5,4 & 0,0 & 1,9 & 2.8 & 6,8 & 7,7 & 39,4 \\
\hline Tocantins & 214378 & 7,3 & 5,8 & 4,5 & 6.7 & 13,1 & 14,5 & 18,6 \\
\hline Nordeste & 8706711 & 35,8 & 25,0 & 33,1 & 43,4 & 52,6 & 59,8 & 68,2 \\
\hline Maranhà & 874174 & 18,3 & 9,1 & 16,1 & 28.5 & 41,9 & 53,9 & 40,0 \\
\hline Pisul & 443469 & 79 & 3,8 & 4,1 & 7,1 & 11,6 & 26,5 & 48,6 \\
\hline Ceara & 1421127 & 29.8 & 20,1 & 27,3 & 34,1 & 48,1 & 56,6 & 66,9 \\
\hline Regia Metropoitana de Fortaleza & 750188 & 42.2 & 29,8 & 38,1 & 45,5 & 57,0 & 63,2 & 73,3 \\
\hline Rio Grande do Norte & 550031 & 17.6 & 13,2 & 17,6 & 23.8 & 19,4 & 17,4 & 25,9 \\
\hline Parabo & 672328 & 40.2 & 30,4 & 36,7 & 56,2 & 62,5 & 68,8 & 56,4 \\
\hline Pemambuco & 1561235 & 38,3 & 29,8 & 34,8 & 41,3 & 53,4 & 55,8 & 70,0 \\
\hline Regiáo Metropolitana de Recile & 884076 & 32.6 & 18,4 & 26,5 & 34.2 & 46,5 & 54,9 & 68,2 \\
\hline Alagoas & 477148 & 20,5 & 11,0 & 17,8 & 32.6 & 33,3 & 28,9 & 75,0 \\
\hline Sergipe & 389116 & 57.1 & 45,6 & 55,5 & 64.9 & 72,2 & 72,2 & 88,7 \\
\hline Bahia & 2318083 & 82,3 & 37,7 & 50,5 & 62.8 & 71,9 & 79,7 & 85,1 \\
\hline Reolao Metropoltana de Salvador & 829344 & 71.9 & 57,8 & 65,6 & 76,4 & 86,2 & 89,9 & 91,9 \\
\hline Sudeste & 19527302 & 84,9 & 68,3 & 19,3 & 85,4 & 90,5 & $\mathbf{y 3 , 3}$ & 95,7 \\
\hline Minas Geras & 4247654 & 82,1 & 67,6 & 78,8 & 86,7 & 91,2 & 92,2 & 94,6 \\
\hline Regias Metropoiltana de Belo Horizonte & 1230970 & 81,6 & 66,0 & 73,7 & 829 & 90,2 & 93,7 & 98,0 \\
\hline Espirito Santo & 721541 & 66,7 & 48,5 & 64,6 & 67,6 & 81,0 & 80,8 & 89,4 \\
\hline Rio de Janeiro & 4332186 & 779 & 59,6 & 70,1 & 77,5 & 83,2 & 87,6 & 92,6 \\
\hline Regiao Metropolitana do Fio de Janeiro & 3401828 & 820 & 63,3 & 73,2 & 81,3 & 88,5 & 90,5 & 95,3 \\
\hline Săo Paulo & 10225921 & 50,3 & 77,2 & 85,0 & 91.2 & 93,7 & 96,2 & 97,5 \\
\hline Regiao Metropolitana de Sáo Paulo & 4951425 & 87,7 & 69,9 & 78,5 & 879 & 93,4 & 95,5 & 97,9 \\
\hline Sul & 6222740 & 57,2 & 37,1 & 45,9 & 55,6 & 65,6 & 73,6 & 80,8 \\
\hline Parand & 2329278 & $\$ 8.2$ & 36,2 & 45,9 & 882 & 71,2 & 79,9 & $89, \mathrm{~B}$ \\
\hline Regiao Metropoitana de Curisba & 738541 & 81,7 & 60,9 & 76,6 & 81.8 & 86,5 & 90,0 & 93,3 \\
\hline Santa Catarina & 1306739 & 50.8 & 37,1 & 41,0 & 48.9 & 52,9 & 62,2 & 65,6 \\
\hline Rio Grande do Sul & 2586723 & 89.5 & 38,2 & 48,6 & 56,9 & 68,4 & 75,4 & 81,5 \\
\hline Reglao Metropoltana de Porso Alegre & 1134363 & $\pi 7,4$ & 58,5 & 68,5 & 72.9 & 84,2 & 88,3 & 92,4 \\
\hline Centro-Oeste & 2907204 & 38,3 & 23,6 & 28,0 & 37,6 & 50,3 & 57,3 & 69,3 \\
\hline Mato Grosso do Sul & 517301 & 10.7 & 5,0 & 5,1 & 92 & 11,5 & 25,8 & 36,7 \\
\hline Mato Groaso & 554079 & 202 & 12,2 & 12,8 & 20,3 & 28,2 & 29,4 & 43,3 \\
\hline Gaisa & 1283543 & 36,3 & 19,1 & 28,6 & 39.8 & 54,3 & 62,0 & 66,0 \\
\hline Distribo Federal & 552281 & 870 & 75,3 & 82,2 & 89.4 & 90,4 & 90,4 & 93,0 \\
\hline
\end{tabular}

Fonte: Pesquisa nacional por amostra de domicllos 2001: microdados. Rio de Janeiroc IBGE, 2002. 1 CD-ROM.

Notax (1) inclusive os sem declaraçso e sem rendimento. 
Tabela 17 - Pessoas residentes em domicílios particulares, total e sua respectiva distribuição percentual, por classes de rendimento mensal familiar per capita em salário mínimo, segundo as Grandes Regióes, Unidades da Federação e

Regióes Metropolitanas - 2001

\begin{tabular}{|c|c|c|c|c|c|c|c|}
\hline \multirow{3}{*}{$\begin{array}{l}\text { Grandes Regioes, } \\
\text { Unidades da Federaçao e } \\
\text { Regioes Metropolitanas }\end{array}$} & \multicolumn{7}{|c|}{ Pessoas residentes em domicilios particulares } \\
\hline & \multirow{2}{*}{$\begin{array}{l}\text { Total } \\
\text { (1) }\end{array}$} & \multicolumn{6}{|c|}{$\begin{array}{l}\text { Classes de rendimento mensal familliar per capita em } \\
\text { salario minimo ( } \mathrm{\psi})\end{array}$} \\
\hline & & $\begin{array}{l}\text { Ats } \\
1 / 2\end{array}$ & $\begin{array}{l}\text { Mals } \\
\text { de } 1 / 2 \\
\text { atd } 1\end{array}$ & $\begin{array}{l}\text { Mals } \\
\text { de a } 2\end{array}$ & $\begin{array}{c}\text { Mais } \\
\text { de a } 3\end{array}$ & $\begin{array}{l}\text { Mais } \\
\text { de } \\
3 \text { a } 5\end{array}$ & $\begin{array}{l}\text { Mais } \\
\text { de } 5\end{array}$ \\
\hline Brasil (2) & 168708585 & 29,0 & 24,3 & 21,0 & 8,1 & 6,4 & 6,0 \\
\hline Norte (3) & 9389067 & 34,9 & 28,0 & 18,5 & 6,0 & 4,2 & 3,5 \\
\hline Rondoria & 914225 & 28,7 & 29,0 & 22,5 & 6,5 & 5,0 & 4,4 \\
\hline Acre & 384271 & 32,6 & 22,4 & 18,2 & 6,9 & 6,6 & 6,3 \\
\hline Amazonas & 2179175 & 36,1 & 25,9 & 18,1 & 6,8 & 3,9 & 3,3 \\
\hline Roraima & 261355 & 28,7 & 28,4 & 21,1 & 7,5 & 6,2 & 2,8 \\
\hline Pard & 4304305 & 38,4 & 28,3 & 16,7 & 5,1 & 3,7 & 3,0 \\
\hline Regiao Metropoltana de Belém & 1797411 & 32,0 & 25,9 & 18.9 & 6,0 & 5,3 & 4,8 \\
\hline Amapá & 448589 & 16,2 & 33.5 & 26,1 & 10,4 & 5,2 & 4,1 \\
\hline Tocartins & 1181702 & 42,6 & 27.8 & 15.8 & 4,1 & 3,4 & 3,1 \\
\hline Nordeste & 48266817 & 50,9 & 23,5 & 11,7 & 3,5 & 2,6 & 2,4 \\
\hline Maranhaso & 5733974 & 56,9 & 23.2 & 9,4 & 3,5 & 2,2 & 1,4 \\
\hline Pisul & 2860112 & 53,0 & 22,9 & 11,3 & 3,4 & 2,1 & 2,0 \\
\hline Ceard & 7531066 & 52,1 & 230 & 11,9 & 3,4 & 2,2 & 2,6 \\
\hline Regias Metropelitana de Fertaleza & 2032303 & 28,8 & 242 & 16,1 & $\varepsilon, 1$ & 4,0 & 5,4 \\
\hline Rio Grande do Norte & 2818275 & 45,5 & 26,4 & 14.6 & 4,4 & 2,9 & 2,9 \\
\hline Paraba & 3466360 & 54,5 & 23.0 & 10.2 & 3,0 & 3,1 & 2,3 \\
\hline Pemambuco & 8002558 & 46,5 & 23.5 & 13,3 & 3,9 & 3,0 & 3,0 \\
\hline Regias Metropolitana de Recile & 3380197 & 32,8 & 25,7 & 16.6 & 6,0 & 5,4 & 5,9 \\
\hline Alsogoas & 2857610 & 57,4 & 229 & 9,2 & 2,8 & 2,1 & 2,1 \\
\hline Sergipe & 1820727 & 45,2 & 24,5 & 14,4 & 4,0 & 3,0 & 2,9 \\
\hline Bahia & 13176136 & 49,5 & 23,7 & 11,6 & 3,2 & 2,7 & 2,2 \\
\hline Regiao Metropolitana de Salvador & 3065816 & 30,1 & 25,9 & 16,9 & 6,9 & 5,9 & 6,2 \\
\hline Sudeste & 73468386 & 17,8 & 23,6 & 25,1 & 10,6 & 8,7 & 8,2 \\
\hline Minas Geras & 18108675 & 28,5 & 27,8 & 21,0 & 7,8 & 5,8 & 4,6 \\
\hline Regia Metropolitana de Belo Horizonte & 4440281 & 18,4 & 27,1 & 23,4 & 9,6 & 8,1 & 7,5 \\
\hline Espirito Santo & 3156915 & 32,0 & 24,3 & 20,0 & 7,3 & 5,8 & 5,4 \\
\hline Rio de Janeiro & 14561924 & 15,9 & 23,3 & 25,3 & 11,2 & 8,6 & 9,1 \\
\hline Regià Metropoitana do Fio de Janeico & 11008028 & 14,3 & 21,6 & 25,6 & 11,8 & 9,1 & 10,0 \\
\hline Sâo Paulo & 37640872 & 12,3 & 21,7 & 27,4 & 12,1 & 10,3 & 9,9 \\
\hline Regiáo Metropolitana de Sao Paulo & 18108210 & 11,3 & 19.8 & 25,6 & 12,1 & 10,8 & 11,1 \\
\hline Sul & 25421732 & 19,1 & 24,8 & 27,5 & 10,8 & 7,9 & 6,8 \\
\hline Parand & 9687606 & 22,5 & 25,9 & 25,0 & 9,7 & 6,8 & 6,3 \\
\hline Regiao Metropoitana de Curbba & 2807247 & 13,7 & 229 & 27.0 & 12,7 & 9,5 & 9,8 \\
\hline Santa Catarina & 5444206 & 12,8 & 25,3 & 30.6 & 12,8 & 9,5 & 6,4 \\
\hline Ria Grande do Sul & 10289920 & 19,1 & 23,4 & 28.2 & 10,8 & 8,1 & 7,5 \\
\hline Regia Metropolitana de Porto Alegre & 3763406 & 13,3 & 21.2 & 28,5 & 12,5 & 10,2 & 11,2 \\
\hline Centro-Oeste & 11378028 & 24,6 & 28,4 & 21,8 & 7,7 & 6,4 & 7,0 \\
\hline Mato Grosso do Sul & 2114174 & 24,4 & 30,5 & 220 & 7,8 & 6,2 & 5,5 \\
\hline Mato Grosso & 2563318 & 25,8 & 28,4 & 23.6 & 6,8 & 5,8 & 5,6 \\
\hline Goiss & 5105843 & 26,8 & 30,7 & 22.2 & 6,9 & 5,1 & 4,6 \\
\hline Distribo Federal & 2094693 & 18,1 & 20.8 & 18.7 & 10,8 & 10,6 & 16,1 \\
\hline
\end{tabular}

Fonte: Pesquisa nacional por amestra de domiclios 2001: microdados. Rio de Janeiro IBGE, 2002. 1 CD-ROM. Notax (1) Inclusive as famalias sem declaraçso sem rendimento.

(2) Exclusive a populaçso rural de Rondoria, Acre, Amazonas, Roraima, Pard e Amapa.

(3) Exclusive a populaçso rural. 
Tabela 18 - Número médio de pessoas, na família, residentes em domicílios particulares, por classes de rendimento mensal familiar per capita em salário mínimo, segundo as Grandes Regióes, Unidades da Federação e Regiões Metropolitanas - 2001

\begin{tabular}{|c|c|c|c|c|c|c|c|c|}
\hline \multirow{3}{*}{$\begin{array}{l}\text { Grandes Regices, } \\
\text { Unidades da Federaça e } \\
\text { Regioes Metropolitanas }\end{array}$} & \multicolumn{8}{|c|}{$\begin{array}{l}\text { Nümero médio de pessoas, na familia, residentes em } \\
\text { domicillios particulares }\end{array}$} \\
\hline & \multirow{2}{*}{$\begin{array}{c}\text { Total } \\
\text { (1) }\end{array}$} & \multicolumn{7}{|c|}{$\begin{array}{l}\text { Classes de rendimento mensal familiar per capita } \\
\text { em salario minimo }\end{array}$} \\
\hline & & Até $1 / 4$ & $\begin{array}{l}\text { Mals } \\
\text { de } 1 / 4 \\
\text { ate } 1 / 2\end{array}$ & $\begin{array}{l}\text { Mais de } \\
1 / 2 \text { ate } 1\end{array}$ & $\begin{array}{c}\text { Mais de } \\
1 \text { a } 2\end{array}$ & $\begin{array}{c}\text { Mais do } \\
2 \text { a } 3\end{array}$ & $\begin{array}{l}\text { Mals de } \\
3 \text { a } 5\end{array}$ & $\begin{array}{c}\text { Mais de } \\
5\end{array}$ \\
\hline Brasil (2) & 3,3 & 4,8 & 3,9 & 3,4 & 3,1 & 3,0 & 2,9 & 2,6 \\
\hline Norte (3) & 3,7 & 5,1 & 4,2 & 3,7 & 3,3 & 3,1 & 3,0 & 2,7 \\
\hline Rondónia & 3,5 & 4,6 & 4,0 & 3,5 & 3,3 & 3,2 & 3,0 & 2,9 \\
\hline Acre & 3,6 & 4,7 & 4,3 & 3,6 & 3,3 & 3.2 & 3,2 & 2,7 \\
\hline Aullazurlas & 3,8 & B,4 & 4,9 & 3,8 & 3,4 & 3,2 & 3,0 & $2, T$ \\
\hline Roraims & 3,9 & 5,5 & 4,6 & 3,9 & 3,7 & 3,4 & 3,1 & 2,5 \\
\hline Pard & 3,7 & 5,1 & 4,2 & 3,6 & 3,2 & 3.2 & 3,0 & 2,8 \\
\hline Regiao Metropolitana de Beidem & 3,5 & 4,6 & 3,9 & 3,5 & 3,2 & 3.2 & 3,0 & 2,7 \\
\hline Amapd & 3,4 & 7,0 & 5,0 & $3, \mathrm{~B}$ & 3,2 & 2,7 & 2,3 & 2,2 \\
\hline Tocartins & 3,6 & 4,8 & 4,1 & 3,4 & 3,2 & 3,2 & 3,2 & 2,5 \\
\hline Nordeste & 3,6 & 4,8 & 4,0 & 3,2 & 2,9 & 3,0 & 3,0 & 2,7 \\
\hline Maranhào & 4,0 & 5,1 & 4,3 & 3,5 & 3,0 & 3,3 & 3,1 & 3,0 \\
\hline Piaul & 3,7 & 4,7 & 4,0 & 3,3 & 3,0 & 3,0 & 2,8 & 2,7 \\
\hline Ceard & 3,6 & 4,7 & 4,0 & 3,1 & 3,0 & 3,0 & 2,9 & 2,7 \\
\hline Regiao Metropoltana de Fortaleza & 3,4 & 4,7 & 3,9 & 3,3 & 3,1 & 3,1 & 3,0 & 2,7 \\
\hline Rio Grande do Norte & 3,5 & 4,7 & 3,9 & 3,2 & 3,0 & 3.2 & 3,1 & 2,9 \\
\hline Parabo & 3,6 & 4,9 & 3,9 & 3,0 & 3,1 & 3,3 & 3,3 & 2,7 \\
\hline Pemambuco & 3,5 & 4,9 & 4,0 & 3,3 & 2,8 & 2,9 & 3,0 & 2,6 \\
\hline Regia Metropoltana de Recife & 3,3 & 4,3 & 3,9 & 3,4 & 3,0 & 2,9 & 3,1 & 2,7 \\
\hline Alsgoas & 3,7 & 4,9 & 4,1 & 3,2 & 2,9 & 3.0 & 3,0 & 2,9 \\
\hline Sergipe & 3,4 & 4,8 & 3,8 & 3,3 & 2,8 & 2.8 & 2,8 & 2,9 \\
\hline Bahia & 3,6 & 4,8 & 3,9 & 3,2 & 2,9 & 2,9 & 2,9 & 2,5 \\
\hline Regiao Metropolitana de Salvsdor & 3,3 & 4,3 & 3,9 & 3,4 & 3,0 & 2,9 & 2,9 & 2,5 \\
\hline Sudeste & 3,2 & 4,6 & 3,9 & 3,4 & 3,2 & 3,0 & 2,9 & 2,6 \\
\hline Minas Geras & 3,3 & 4,6 & 3,8 & 3,3 & 3,1 & 3.0 & 3,0 & 2,5 \\
\hline Regiao Metropoltana de Beia Horizonte & 3,3 & 4,8 & 3,7 & 3,6 & 3,3 & 2,9 & 3,0 & 2,6 \\
\hline Espirito Santo & 3,3 & 4,5 & 3,8 & 3,3 & 3,0 & 3.0 & 3,1 & 2,6 \\
\hline Rio de Janeira & 3,0 & 4,8 & 3,7 & 3,3 & 3,0 & 2.8 & 2,7 & 2,3 \\
\hline Regiao Metropolitana do Foo de Janeiro & 3,0 & 4,9 & 3,7 & 3,3 & 3,0 & 2.8 & 2,6 & 2,3 \\
\hline Săo Paulo & 3,3 & 4,5 & 4,0 & 3,5 & 3,3 & 3,0 & 3,0 & 2,7 \\
\hline Regiao Metropoltana de Sao Paulo & 3,3 & 4,6 & 4,1 & 3,6 & 3,3 & 3,1 & 3,0 & 2,7 \\
\hline Sul & 3,2 & 4,5 & 3,8 & 3,4 & 3,1 & 2,9 & 2,8 & 2,4 \\
\hline Parand & 3,3 & 4,7 & 3,8 & 3,4 & 3,1 & 3.0 & 2,8 & 2,7 \\
\hline Regiáo Metropoltana de Curisba & 3,2 & 4,6 & 3,9 & 3,6 & 3,2 & 3.0 & 2,8 & 2,6 \\
\hline Santa Catarina & 3,2 & 4,6 & 4,0 & 3,5 & 3,2 & 3,0 & 2,9 & 2,4 \\
\hline Rio Grande do Sul & 3,0 & 4,3 & 3,8 & 3,3 & 2,9 & 2,7 & 2,7 & 2,3 \\
\hline Regias Metropolitana de Porto Alegre & 3,0 & 4,4 & 3,9 & 3,4 & 3,0 & 2,7 & 2,7 & 2,3 \\
\hline Centro-Oeste & 3,3 & 4,5 & 3,8 & 3,4 & 3,1 & 3,0 & 2,9 & 2,7 \\
\hline Mato Grosso do Sul & 3,3 & 4,5 & 3,7 & 3,3 & 3,0 & 2,9 & 3,0 & 2,9 \\
\hline Mato Grosso & 3,4 & 4,7 & 4,0 & 3,5 & 3,1 & 2,9 & 2,9 & 2,8 \\
\hline Goiss & 3,2 & 4,4 & 3,7 & 3,3 & 3,1 & 2,9 & 2,8 & 2,6 \\
\hline Distribo Federal & 3,3 & 4,6 & 4,1 & 3,6 & 3,2 & 3,3 & 3,2 & 2,7 \\
\hline
\end{tabular}

Fonte: Pesquisa nacional por amostra de domicilos 2001: microdados. Rio de Janeiroc IBGE, 2002. 1 CD-ROM.

Nota: Exclusive as pessoas cuja condiçalo na familia era pensianista, empregado domestico e parente do empregado dombstico.

(1) Inclusive as familias sem declaraçăo e sem rendimento.

(2) Exclushe a populaçào nural de Randonia, Acre, Amazonas, Roraima, Para e Amapd.

(3) Exclusine a populaçàa nural. 


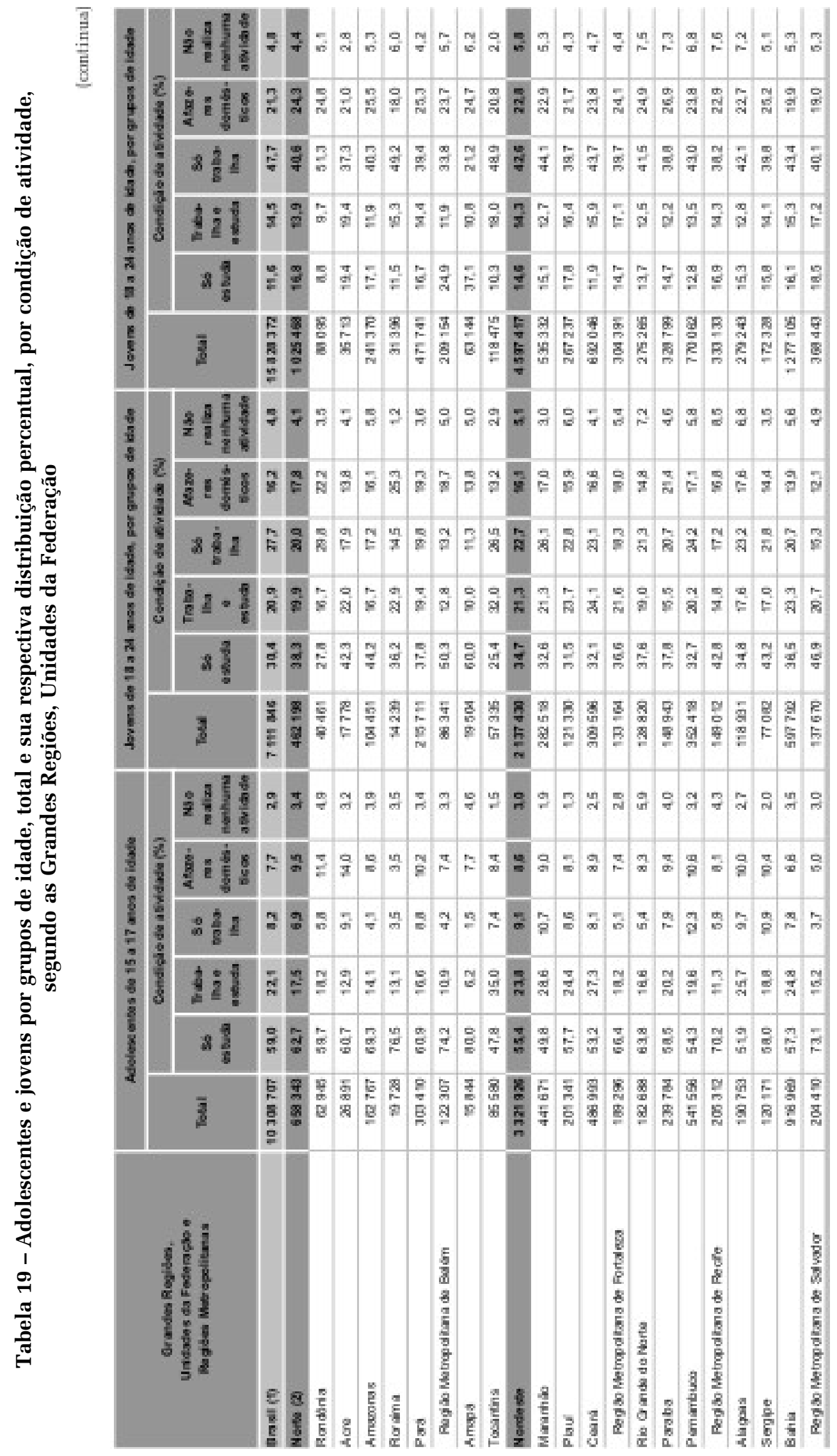




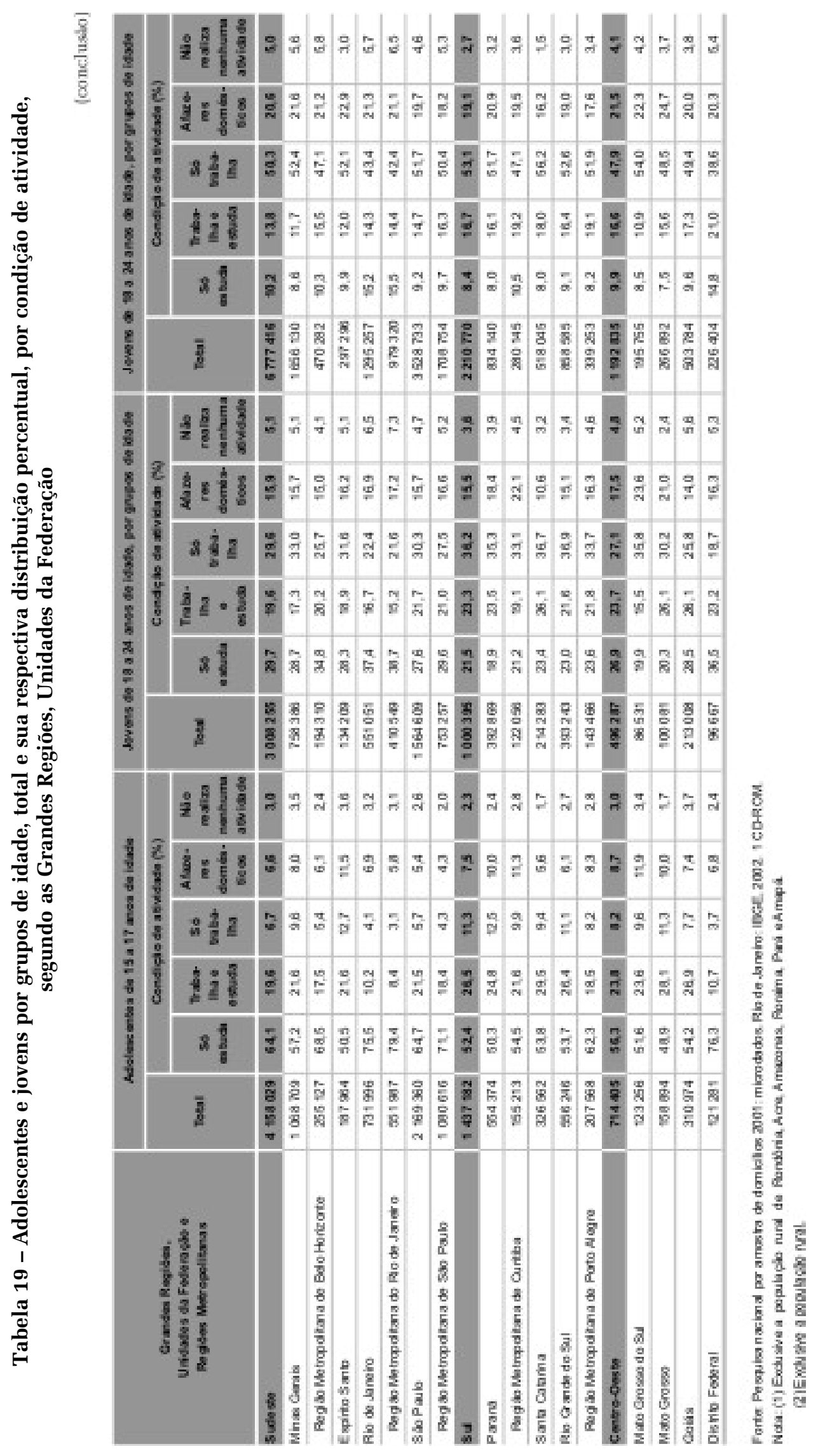


Tabela 20 - Pessoas de 60 anos ou mais de idade, residentes em domicílios particulares permanentes, total e sua respectiva distribuição, por classes de rendimento médio mensal familiar per capita em salário mínimo, segundo as Grandes Regiões, Unidades da Federação e Regióes Metropolitanas - 2001

\begin{tabular}{|c|c|c|c|c|c|c|c|c|}
\hline \multirow{3}{*}{$\begin{array}{l}\text { Grandes Regioes, } \\
\text { Unidades da Federaçto e } \\
\text { Regioes Metropolitanas }\end{array}$} & \multicolumn{8}{|c|}{ Pessoas de 60 anos ou mais de idade } \\
\hline & & \multicolumn{7}{|c|}{$\begin{array}{l}\text { Classes de rendimento médio mensal famillar } \\
\text { por capita em salario minimo [S] }\end{array}$} \\
\hline & Total (1) & $\begin{array}{l}\text { Atd } \\
1 / 4\end{array}$ & $\begin{array}{l}\text { Mais } \\
\text { de } 1 / 4 \\
\text { ate } 1 / 2\end{array}$ & $\begin{array}{c}\text { Mais de } \\
1 / 2 \text { a } 1\end{array}$ & $\begin{array}{c}\text { Mals de } \\
1 \text { a } 2\end{array}$ & $\begin{array}{c}\text { Mais de } \\
2 \text { a } 3\end{array}$ & $\begin{array}{c}\text { Mais de } \\
3 \text { a } 5\end{array}$ & $\begin{array}{l}\text { Mais } \\
\text { de } 5\end{array}$ \\
\hline Brasil (2) & 15321014 & 2,3 & 10,4 & 28,7 & 26,2 & 10,1 & 8,9 & 9,7 \\
\hline Norte (3) & 525819 & 3,1 & 15,0 & 35,5 & 26,0 & 6,5 & 6,4 & 5,8 \\
\hline Rondoria & $\$ 6415$ & 3,3 & 15,6 & 36,3 & 26,4 & 8,3 & 4,0 & 5,1 \\
\hline Acre & 21833 & 2,0 & 11,2 & 29,1 & 29,8 & 7,3 & 12,6 & 6,6 \\
\hline Amazonas & 100383 & 4,9 & 14,7 & 29,5 & 23,7 & 10,4 & 9,0 & 5,5 \\
\hline Roraims & 13224 & 2,6 & 9,1 & 32,5 & 24,7 & 7,8 & 13,0 & 2,6 \\
\hline Para & 244734 & 2,9 & 15,1 & 36,9 & 26,5 & 5,2 & 5,2 & 6,6 \\
\hline Regiao Metropolitana de Beldem & 104552 & 3,6 & 12,1 & 28,0 & 27,2 & 5,8 & 9,2 & 11,5 \\
\hline Amapá & 29253 & 0,8 & 11,7 & 38,3 & 34,2 & 6,7 & 4,2 & 4,2 \\
\hline Tocantins & 89582 & 5,4 & 18,1 & 40,9 & 22,6 & 3,1 & 4,7 & 3,5 \\
\hline Nordeste & 4238112 & 4,9 & 17,7 & 40,7 & 20,8 & 4,7 & 3,9 & 4,2 \\
\hline Maranhaso & 419580 & 6,2 & 23,0 & 41,9 & 15,6 & 4,0 & 4,4 & 2,9 \\
\hline Pisul & 281351 & 3,2 & 17.8 & 42,2 & 22,3 & 5,4 & 3,2 & 4,3 \\
\hline Cearat & 694078 & 3,6 & 15,4 & 44,2 & 20,5 & 4,8 & 3,2 & 4,9 \\
\hline Regias Metrepolitana de Fertaleca & 212491 & 2,7 & 12,2 & 20,4 & 22,6 & 0,0 & 7,0 & 12,8 \\
\hline Rio Grande do Norte & 249305 & 5,9 & 16,5 & 45,2 & 18,9 & 4,1 & 4,1 & 3,9 \\
\hline Paraibs & 354765 & 4,4 & 20,0 & 48,9 & 14,8 & 4,7 & 3,2 & 3,3 \\
\hline Pemambuce & 685253 & 3,8 & 14,7 & 34,3 & 27,7 & 6,4 & 4,6 & 5,3 \\
\hline Regiao Metropolitana de Recile & 278955 & 2,0 & 12,9 & 26,0 & 24,1 & 9,7 & $\mathrm{~B}, \mathrm{9}$ & 11,5 \\
\hline Alogoas & 233587 & 7,7 & 20,0 & 38,3 & 19,8 & 5,1 & 4,3 & 4,5 \\
\hline Sergipe & 131952 & 4,8 & 16,6 & 34,7 & 25,8 & 7,4 & $3, \mathrm{~B}$ & 3,8 \\
\hline Bahia & 1178228 & 5,6 & 18,0 & 39,3 & 20,3 & 3,6 & 3,9 & 4,1 \\
\hline Regiáo Metropolitana de Sahrador & 211765 & 3,6 & 11,7 & 23,7 & 20,9 & 8,5 & 11,0 & 13,6 \\
\hline Sudeste & 7215581 & 1,3 & 7,1 & 22,1 & 27,1 & 12,9 & 11,8 & 13,0 \\
\hline Minas Gerais & 1760444 & 2,0 & 11,1 & $33, \mathrm{~B}$ & 26,1 & 9,1 & 6,9 & 7,9 \\
\hline Regiao Metropolitana de Belo Harizonle & 360175 & 1,6 & 6,9 & 25,5 & 25,6 & 13,2 & 9,1 & 12,9 \\
\hline Espirino Sarno & 245334 & 1,8 & 9.4 & 26,2 & 31,7 & 9,8 & $\mathrm{~B}, 7$ & 10,1 \\
\hline Rio de Janeiro & 1702714 & 0,9 & 5,3 & 17,9 & 23,7 & 15,9 & 12,9 & 17,7 \\
\hline Regiào Metropolitana do Rio de Janeiro & 1337715 & 0,9 & 4,3 & 15,8 & 23,7 & 16,8 & 13,3 & 18,6 \\
\hline Sàn Paulo & 3607 0s9 & 1,1 & 5.8 & 18,1 & 28,9 & 13,6 & 13,9 & 13,5 \\
\hline Regiao Metropoltana de Sà Paulo & 1562231 & 1,4 & 5.4 & 14,1 & 26,4 & 13,2 & 15,0 & 16,3 \\
\hline Sul & 2494659 & 1,0 & 6,7 & 24,8 & 32,3 & 12,7 & 10,1 & 10,2 \\
\hline Parand & 872743 & 1,4 & 7,7 & 27,4 & 31,1 & 10,5 & $\mathrm{~B}, 7$ & 9,7 \\
\hline Regiäo Metropolitana de Curitiba & 232808 & 1,9 & 4,7 & $18, \mathrm{~B}$ & 27,2 & 14,4 & 12,2 & 17,2 \\
\hline Santa Catarina & 490665 & 0,3 & 5,3 & 25,9 & 36,4 & 12,5 & 10,9 & 7,8 \\
\hline Rio Grande do Sul & 1131290 & 0,9 & 5.4 & 22,3 & 32,0 & 14,4 & 10,9 & 11,6 \\
\hline Regiào Metropolitana de Porto Alogre & 370 oro & 0,9 & 4.6 & 15,3 & 27,8 & 16,5 & 13,2 & 18,9 \\
\hline Centro-Oeste & 817198 & 1,7 & 11,3 & 31,7 & 27,3 & 7,9 & 7,4 & 9,9 \\
\hline Mato Grosso do Sul & 184854 & 1,0 & 13,5 & 34,4 & 25,9 & 9,3 & 7,3 & 6,4 \\
\hline Mato Grosso & 149615 & 3,9 & 11,5 & 29,0 & 29,2 & 6,9 & 6,7 & 8,3 \\
\hline Goids & 378172 & 1,3 & 11,3 & 35,3 & 29,5 & 7,1 & 6,2 & 72 \\
\hline Distribo Federal & 104547 & 1,1 & 7,3 & $1 \mathrm{~B}, 1$ & 19,2 & 9,2 & 13,4 & 28,4 \\
\hline
\end{tabular}

Fonte: Pesquisa nacional por amestra de domiclios 2001: microdados. Rio de Janeiro: IBGE, 2002. 1 CD-ROM. Notac (1) Inclusive sem rendimento e sem declaraçso de rendimento.

(2) Exclusive a populaçso rural de Rondónia, Acre, Amazonas, Roraima, Para e Amapa.

(3) Exclusive a populaçso rural. 
Tabela 21 - Taxa de analfabetismo na população de 15 anos ou mais por rendimento domiciliar segundo a Unidade da Federação - Brasil 2001

\begin{tabular}{|c|c|c|c|c|c|c|}
\hline \multirow{2}{*}{ Unidade da Federaç, to } & \multirow{2}{*}{ Total } & \multicolumn{5}{|c|}{ Rendimento Dominciliar em Salario Minimo Corrente (\%) (1) (2) } \\
\hline & & Ate $1 \mathrm{sM}$ & $\begin{array}{c}\text { Mais de } 1 \text { atd } \\
3 \mathrm{sM}\end{array}$ & $\begin{array}{c}\text { Mais de } 3 \text { ate } \\
5 \mathrm{sM}\end{array}$ & $\begin{array}{c}\text { Mais de } 5 \text { atd } \\
105 \mathrm{M}\end{array}$ & $\begin{array}{c}\text { Mais de } 10 \\
\text { SM }\end{array}$ \\
\hline Brasil & 12,4 & 28,8 & 19,7 & 9,7 & 4,7 & 1,4 \\
\hline Norte & 11,2 & 22,5 & 15.5 & 9,9 & 5,0 & 2,0 \\
\hline Rondônis & 10,2 & 25,9 & 15.0 & 7,2 & 4,3 & 1,3 \\
\hline Acre & 16,7 & 29,4 & 23,1 & 22,2 & 7,1 & 2,9 \\
\hline Amazonas & 7,7 & 15,8 & 11,1 & 6,3 & 3,9 & 2,2 \\
\hline Roraima & 11,5 & 17,0 & 16,9 & 11,4 & 9,1 & 2,4 \\
\hline Para & 11,2 & 20,3 & 14.9 & 11,0 & 5,2 & 2,0 \\
\hline Amapd & 7,2 & 21,7 & 8.5 & 6,0 & 5,4 & 0,7 \\
\hline Tocantina & 18,5 & 34,3 & 240 & 13,4 & 5,5 & 2,3 \\
\hline Nordeste & 24,3 & 35,8 & 29.3 & 17,2 & 8,4 & 1,8 \\
\hline Moranhāo & 23,4 & 34,2 & 279 & 15,5 & 10,9 & 4,0 \\
\hline Piaul & 29,4 & 40,4 & 35,3 & 21,7 & 11,7 & 2,4 \\
\hline Ceara & 24,8 & 38,1 & 29,3 & 17,7 & 8,7 & 1,3 \\
\hline R. G. do Narte & 24,2 & 35,3 & 30,7 & 20,0 & 8,7 & 1,2 \\
\hline Paralba & 27,2 & 39,4 & 32.5 & 19,0 & 9,3 & 0,8 \\
\hline Pernambudo & 22,0 & 34,9 & 279 & 16,7 & 7,4 & 2,2 \\
\hline Alagoas & 30,6 & 47,1 & 34,7 & 18,1 & 9,5 & 1,9 \\
\hline Sergipe & 21,4 & 35,2 & 24.8 & 14,4 & 7,1 & 1,8 \\
\hline Bahia & 22,9 & 34,7 & 27,5 & 16,2 & 7,0 & 1,1 \\
\hline Sudeste & 7,5 & 20,0 & 13.5 & 7,5 & 4,0 & 1,5 \\
\hline Mnas Gerais & 11,7 & 22,9 & 179 & 9,8 & 4,5 & 1,8 \\
\hline Espinto Santo & 11,5 & 23,1 & 14,5 & 11,6 & 5,5 & 2,4 \\
\hline Ro de Janeiro & 5,6 & 17,7 & 9.8 & 5,4 & 3,3 & 1,2 \\
\hline Sao Paula & 6,0 & 17,6 & 11,6 & 7,0 & 3,9 & 1,5 \\
\hline sul & 7,1 & 19,5 & 12.4 & 5,9 & 3,6 & 0,8 \\
\hline Paraná & 8,6 & 22,1 & 14,1 & 6,8 & 4,0 & 0,7 \\
\hline Santa Catarina & 5,9 & 17,8 & 11,3 & 5,4 & 4,1 & 1,0 \\
\hline R. G. do Sul & 6,3 & 16,8 & 11,3 & 5,4 & 3,0 & 0,8 \\
\hline Centro-Oeste & 10,2 & 23,3 & 15,3 & 8,9 & 5,0 & 1,4 \\
\hline M. G. do Sul & 10,3 & 22,5 & 14,7 & 8,4 & 5,6 & 1,9 \\
\hline Mato Grosso & 11,2 & 26,7 & 14.8 & 9,6 & 5,9 & 1,7 \\
\hline Goias & 11,7 & 24,1 & 16,9 & 9,0 & 4,9 & 1,6 \\
\hline Dstrito Federal & 5,5 & 15,0 & 10.2 & 7,9 & 3,7 & 0,9 \\
\hline
\end{tabular}

Fonte: IBGE - PNAD 2001. / Tabela elaborada pelo INEP a partir dos microdados da PNAD 2001.

Notax Exclusive populaça rural de Ronoboria, Acre, Amazonas, Roraima, Para e Amapa.
(1) Salsrio Minimo $\mathrm{cm} 2001=\mathrm{R} \$ 180,00$.
(2) O calculo destas tama náo lewou em considerap̧so as informoçoes com renda nâo declarada.
(3) Exclusive a populsçato indigena. 


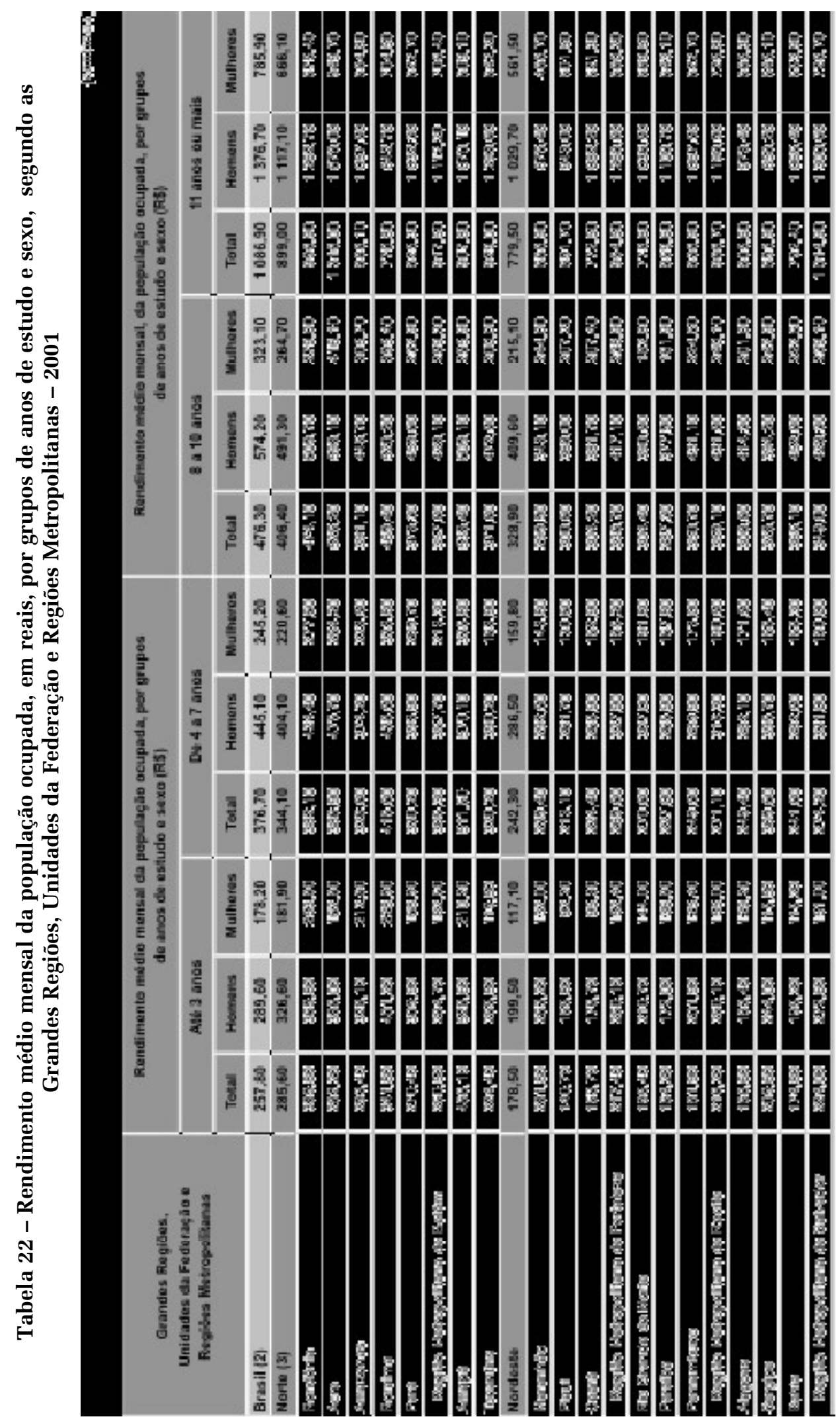




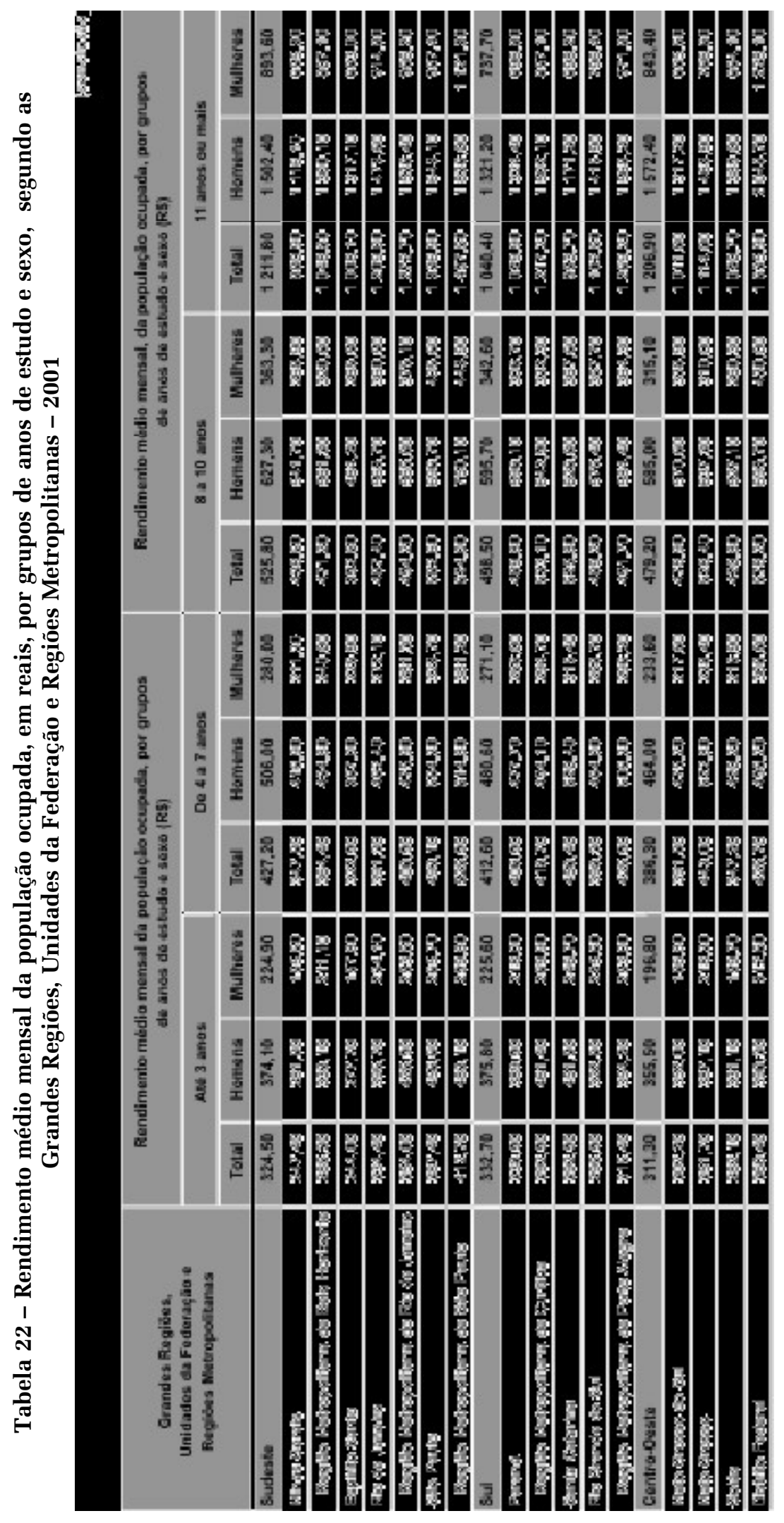

